\title{
The Welfare Effects of Metering Ties
}

\section{Citation}

Einer Elhauge \& Barry J. Nalebuff, The Welfare Effects of Metering Ties (Harvard John M. Olin Discussion Paper Series Paper No. 822, Apr. 2015).

\section{Published Version}

http://www.law.harvard.edu/programs/olin_center/papers/pdf/Elhauge_822.pdf

\section{Permanent link}

http://nrs.harvard.edu/urn-3:HUL.InstRepos:17743077

\section{Terms of Use}

This article was downloaded from Harvard University's DASH repository, and is made available under the terms and conditions applicable to Other Posted Material, as set forth at http:// nrs.harvard.edu/urn-3:HUL.InstRepos:dash.current.terms-of-use\#LAA

\section{Share Your Story}

The Harvard community has made this article openly available.

Please share how this access benefits you. Submit a story.

\section{Accessibility}




\title{
HARVARD
}

JOHN M. OLIN CENTER FOR LAW, ECONOMICS, AND BUSINESS

THE WELFARE EFFECTS OF METERING TIES

\author{
Einer Elhauge \\ Barry J. Nalebuff \\ Discussion Paper No. 822 \\ $04 / 2015$ \\ Harvard Law School \\ Cambridge, MA 02138
}

This paper can be downloaded without charge from:

The Harvard John M. Olin Discussion Paper Series:

http://www.law.harvard.edu/programs/olin_center/

The Social Science Research Network Electronic Paper Collection: http://ssrn.com/abstract=2591577 


\title{
THE WELFARE EFFECTS OF METERING TIES
}

Einer Elhauge and Barry Nalebuff*

April 6, 2015

\begin{abstract}
Critics of current tying doctrine argue that metering ties can increase consumer welfare and total welfare without increasing output and that they generally increase both welfare measures. Contrary to those claims, we prove that metering ties lower consumer welfare and total welfare unless they increase capital good output. We further provide conditions under which metering ties always harm consumer welfare for all uniform and lognormal distributions of consumable usage rates. Finally, we show that with a lognormal distribution, metering ties also lower total welfare absent a large dispersion in desired usage of the metered good. These findings support current tying doctrine, which presumptively condemns ties with market power absent proof of an offsetting procompetitive justification.
\end{abstract}

JEL Codes: C72, K21, L12, L40, L41, L42.

Keywords: tying, ties, antitrust, quasi per se rule, bundling, requirements ties, metering, price discrimination, extracting consumer surplus, consumer welfare, foreclosure share.

\footnotetext{
* Respectively, Petrie Professor of Law, Harvard Law School, and Milton Steinbach Professor of Management, Yale School of Management. We thank Keith Chen, James Dana, seminar participants at UCLA and Yale SOM for helpful feedback.
} 


\section{THE WELFARE EFFECTS OF METERING TIES}

\section{INTRODUCTION}

A firm with market power may meter usage of its product by requiring users to purchase at elevated prices a tied product that is needed to use its product. The classic case is tying a capital product, like printers, to a consumable used with the capital product, like ink. Because buyers who use the tying product more often tend to value it more highly, metering ties can achieve a form of price discrimination when market power exists. However, the relationship of usage to value is typically imperfect and thus so is the resulting price discrimination.

Metering ties have been a focus of scholarly attention for a number of reasons. First, many of the Supreme Court cases on tying have involved metering ties. ${ }^{1}$ Second, there is no longer much controversy about ties that foreclose a substantial share of the tied market because even critics of current tying doctrine concede that such ties can be anticompetitive; see Carlton and Heyer (2008), Carlton and Waldman (2012), Crane (1012), Hovenkamp and Hovenkamp (2010), Lambert (2011), and Semararo (2010). Instead, the critics have focused on the fact that current doctrine allows condemnation of ties without proof of a substantial foreclosure share. ${ }^{2}$ Third, although ties without a substantial foreclosure share also exist in other forms that can harm consumer welfare and total welfare, critics of tying doctrine have usually focused on metering ties because their welfare effects have so far seemed the least clearly harmful to consumer welfare or total welfare.

In focusing this paper on metering ties, we distinguish them from non-metering ties that might also harm welfare without creating a substantial foreclosure share. Some ties create fixed bundles of two products. Such non-metering ties are not metering ties because they do not sell more of the tied product to buyers who use the tying product more. However, such ties can achieve inter-product price discrimination when the demand for the two products is not too positively correlated and market power exists over both products; see Elhauge (2009) and

\footnotetext{
${ }^{1}$ See Illinois Tool Works v. Independent Ink, 547 U.S. 28, 32 (2006) (ink used with printers); Int'l Salt Co., Inc. v. United States, 332 U.S. 392 (1947) (salt used with salt-injecting machines); Int'l Bus. Machs. Corp. v. United States, 298 U.S. 131 (1936) (cards used with tabulating machines).

${ }^{2}$ We here address only the direct effect that a metering tie has without any substantial foreclosure share. If a metering tie does foreclose a substantial market share in a way that creates anticompetitive effects that would provide a separate ground for concern.
} 
Economides (2012). Further, Schmalensee (1984) shows that given any normal distribution of buyer values, such a tie always reduces consumer welfare, and also reduces total welfare unless the strength of demand relative to cost is "especially high."

In other non-metering ties, the tie requires each consumer to buy the tied product at an inflated price, but sales of the tied product are not directly related to the usage of the tying product and each buyer purchases multiple units of the tying product over which market power exists; see Nalebuff (2005), Mathewson and Winter (1997), Economides (2012), Burstein (1960), Greenlee, Reitman and Sibley (2008), and Elhauge (2009). Because each buyer has a declining valuation of the tying product with each additional unit purchased, each buyer would enjoy consumer surplus on the tying product if a single profit-maximizing price were charged to that buyer. Such ties are similar to two-part pricing that charges a lump sum for the right to buy the tying product, but such ties create an additional distortion in tied product purchases and can be feasible in situations when two-part pricing is not. Elhauge (2009) and Greenlee, et al. (2008) provide conditions under which such ties always lower consumer welfare, and may also reduce total welfare.

We focus on metering ties not only because many cases and critics of tying doctrine have focused on them, but also because the economics of metering ties has been comparatively more controversial and, somewhat surprisingly, less well developed in rigorous models. Focusing on metering ties also tackles what has so far seemed the form of tie that offers the best case for the critique that the current quasi per se rule is overbroad. That quasi per se rule is really a form of rule of reason review in that it condemns ties only when the plaintiff proves tying market power and the defendant fails to prove any offsetting procompetitive justification. ${ }^{3}$ But critics of the quasi per se rule have argued that even this form of rule of reason review is unwarranted because they claim that metering ties generally benefit both consumer welfare and total welfare; see

\footnotetext{
${ }^{3}$ See Elhauge (2009: 420, 425); Areeda and Hovenkamp (2011: 372-73) (“the Supreme Court permits justifications for ties challenged under the per se rule ... Notwithstanding its development of a 'per se' rule against tying, the Supreme Court has almost always been willing to consider a defendant's offered justifications.... Today, any justification for tying that is theoretically sound can be considered under Supreme Court precedent); see also Areeda and Hovenkamp (2011: 376-382) (showing that five Supreme Court cases have recognized the admissibility of justifications under the quasi per se rule); Elhauge (2011: 368-69).
} 
Hovenkamp and Hovenkamp (2010) and Lambert (2011). ${ }^{4}$ They argue that one should thus make metering ties per se legal absent proof of a substantial foreclosure share.

In our view, a showing that metering ties usually benefit the relevant welfare measure would not warrant a conclusion of per se legality; but a conclusion that most metering ties improve welfare might merit shifting the burden from defendants to plaintiffs who would then have to show this is a case where welfare falls. Per se legality for all metering ties would be unwarranted because even a showing that most metering ties enhance welfare concedes that some metering ties do harm consumer and total welfare. Thus, the sort of case-by-case rule of reason review provided by the quasi per se rule would seem preferable because it would condemn those harmful metering ties, while still allowing defendants to escape liability for metering ties that have net welfare-enhancing effects. But the usual welfare effects of metering ties might bear on whether current law is correct in putting the burden on defendants to justify their metering ties by proving they are welfare-enhancing. ${ }^{5}$ To be sure, the usual welfare effects do not determine the burden issue because the fact that defendants have better access to evidence on the welfare effects of their ties means that putting the burden on defendants will likely lead to more accurate resolutions of welfare effects; see Elhauge (2010). However, if the welfare effects were generally positive, that might support an argument that, notwithstanding the lower error rate that results from putting the burden on defendants, it leads to an increase in overdeterrence of desirable ties that (given their frequency) outweighs the additional underdeterrence of harmful ties that would be created by putting the burden on the plaintiff. ${ }^{6}$

\footnotetext{
${ }^{4}$ Hovenkamp and Hovenkamp, $(2010: 925,928)$ conclude that the "great majority" of metering ties (which they call "variable proportions" ties) benefit both consumer welfare and total welfare, and indeed "only harm consumer welfare in the most flagrant situations."); 927 "consumers likely benefit most of the time"); Lambert, (2011: 934, 939) concluded that metering ties "typically enhance total welfare" and "most instances of metering enhance consumer welfare."

${ }^{5}$ Current law does so because a metering tie by definition exists only when there is tying market power and enough dollar volume to achieve price-discrimination, thus triggering quasi per se rule condemnation unless the defendant proves a justification that offsets any harm and thus results in a net welfare improvement.

${ }^{6}$ For example, suppose that putting the burden on defendants means that defendants can never prove a harmful tie is beneficial but can accurately prove a beneficial tie is beneficial $90 \%$ of the time. Suppose further that putting the burden on plaintiffs means that they can never prove a beneficial tie is harmful but can accurately prove a harmful tie is harmful $70 \%$ of the time. If $60 \%$ of metering ties were beneficial and the other $40 \%$ were harmful, then putting the burden on the defendant would result in inaccurate resolutions $(.60)(.1)=6 \%$ of the time. Putting the burden on the plaintiff would result in inaccurate resolutions (.4)(.3) $=12 \%$ of the time. In this case, one would want to put the burden on the defendant even though most ties are beneficial because we will get more accurate results. But now suppose $90 \%$ of metering ties are beneficial and the other $10 \%$ are harmful. Then putting the burden on the defendant would result in inaccurate resolutions (.9)(.1) $=9 \%$ of the time. Putting the burden on the plaintiff would
} 
In order to address such questions, this Article offers some general results regarding the welfare effects of metering ties. Although in our view consumer welfare is and should be the legal standard (Elhauge 2009, 2011), throughout the following analysis we also address total welfare effects because some argue that the legal standard is or should be total welfare. A consumer welfare standard judges a restraint of trade by whether it harms consumers, whereas a total welfare standard would allow a restraint of trade if it increases firm profits by more than it harms consumer welfare.

Because we are focused on the welfare effects of pure metering ties, we put aside the possibility that the tie might be designed to achieve some productive efficiency, such as lowering product costs or improving quality. If such productive efficiencies exist for a particular tie, they are admissible under the quasi per se rule and could offset any adverse welfare effects we predict here. Here we assess metering ties without such productive efficiencies because they are important to assess the critics' claim that metering ties without a substantial foreclosure share should be deemed categorically or presumptively legal even when no procompetitive justification has been proven.

In analyzing the baseline total welfare effects of metering ties without special productive efficiencies, we first assume the best case for critics of current tying doctrine by assuming that there is zero dissipation of the additional profits reaped from metering ties. In reality, some profit dissipation is likely for three reasons.

(1) Enforcing ties requires costly monitoring or product alterations; see Grimes and Sullivan (2007), Nalebuff (2009).

(2) Firms tend to dissipate some share of increased profits ex post through greater managerial inefficiency, called X-inefficiency; See Leibenstein (1966, 1978a, 1978b); Elhauge (2003), Button and Weyman-Jones (1992), Frantz (1992), Primeaux (1977), and Shelton (1967).

(3) Increasing the profits reaped from market power will cause firms to spend more ex ante in competing to gain positions of market power, which will dissipate some or all of those profits ex ante; see Elhauge (2009), Posner (1975), and Fisher (1985).

result in inaccurate resolutions $(.1)(.3)=3 \%$ of the time. In this case, one would want to put the burden on the plaintiff because that would result in more accurate results. Thus, showing that a slight majority of ties are beneficial would not justify shifting the burden to plaintiffs, but showing that a high percentage of them are would. 
To the extent one believes that any or all of three sources of profit dissipations will occur, then metering ties are more likely to reduce total welfare than our models would predict. We show how our results extend to the case where the combined profit dissipation from these three sources is $10 \%, 25 \%$, and $33 \%$.

We divide our proofs into two Parts. First, in Part II, we offer a general proof that when a firm has market power over a capital good that is used with a consumable for which there is a competitive market, then profitable metering ties - and indeed any form of price discrimination-lowers consumer welfare and total welfare unless it increases output of the capital product. This is analogous to the result previously known about third-degree price discrimination. This paper thus extends that result to all metering ties and second-degree price discrimination whenever a firm has market power over a capital product but there is no market power on the consumable. Part II further proves some specific conditions under which profitable metering ties fail to increase output and thus lower consumer welfare and total welfare. The results in Part II thus support placing the burden on defendants to show, at a minimum, that their metering ties expand capital good output.

Although expanding capital good output is a necessary condition to show that a metering tie increases consumer welfare or total welfare, is not a sufficient condition. A metering tie that leaves output unchanged will reallocate some output from higher-value buyers to lower-value buyers, which standing alone is welfare reducing. Metering ties can enhance welfare only when they increase overall output and the size of that output increase offsets the welfare harm from reallocating some output from higher-value buyers to lower-value buyers. Whether the net welfare effects of metering ties are harmful will turn both on the distribution of buyer types and the welfare standard one uses.

Next, in order to determine what welfare effects are likely, we specify some plausible distributions of buyer types. In the second part of our analysis, Part III, we present a proof that adopts the assumption that there is a lognormal distribution of buyer usage rates. A lognormal distribution fits the usual observation that moderate users of a capital good are more plentiful than the lowest or heaviest users, though the right tail is "heavy" in that the number of large users falls off slower than an exponential distribution.

With a lognormal distribution of buyer usage rates, we provide a model in which metering ties are always profitable and always reduce consumer welfare, even in those cases 
when they increase tying product output. In this model, a lognormal distribution thus suffices to show that metering ties reduce consumer welfare without any need to inquire into tying product output. Under the consumer welfare standard that we believe is legally applicable, this proof supports condemning metering ties unless defendants can show there are special productive efficiencies large enough to offset the consumer welfare losses, or that different assumptions are more realistic to the case at hand and that those different assumptions would turn around the result.

We also show that, with a lognormal distribution, metering ties reduce total welfare unless the standard deviation of the natural log of buyer usage rates is greater than 0.78. Again, this result holds even if the metering tie does increase output of the tying product. (If we assume $10 \%$ profit dissipation, then this threshold would be a standard deviation of 1.03 , with $25 \%$ profit dissipation the threshold rises to 1.74 , and with $33 \%$ profit dissipation the threshold rises to 2.65 . We show these different distributions in Figure 3.) This means that with a lognormal distribution, metering ties lower total welfare unless the distribution of buyer usage rates has a very high dispersion. This is to be expected. While metering creates inefficiencies, its central advantage comes from being able to serve customers with a wide range of usage rates.

In short, even if antitrust law changes to adopt the total welfare standard advocated by others, our lognormal proof still supports condemning metering ties unless the defendant shows usage dispersion is very large, there are special productive efficiencies large enough to offset the total welfare losses, or that different assumptions are more realistic to the case at hand and that those different assumptions would turn around the result.

Finally, we explain, in Part IV, why claims that prior models showed that metering ties generally benefit both consumer welfare and total welfare are incorrect. Part V concludes.

\section{General ReSUltS}

Perfect (or first-degree) price discrimination charges each buyer a price for the tying product that precisely equals its valuation of that product. This clearly reduces consumer welfare (by taking all consumer surplus), but increases total welfare (by selling the product to anyone who values it at or above its marginal cost). In the real world, price discrimination is inevitably imperfect, and falls into two categories. Second-degree price discrimination offers a menu of product options and prices that causes buyers to self-select in ways that imperfectly correlate with their 
willingness to pay. Third-degree price discrimination charges different categories of buyers different prices that roughly correlate to the value that buyers in each category put on the product.

Varian $(1985,1989)$ proves that third-degree price discrimination reduces total welfare unless it increases output. With linear demand, third-degree price discrimination leaves output unchanged and thus reduces total welfare unless there is a category of buyers who would buy none of the product at a single profit-maximizing price but would at the discriminatory price; see Robinson (1969) and Schmalensee (1981).

The status of second-degree price discrimination is less clear. The literature does not provide any general proof of whether second-degree price discrimination can increase total welfare without any output increase. Some scholars argue that the proposition that imperfect price discrimination cannot increase total welfare unless it increases output does not apply to second-degree price discrimination:

Third-degree price discrimination that does not increase output necessarily decreases welfare. This is not true of second-degree price discrimination.... Equally important is the fact that third-degree price discrimination transfers output from higher-value to lowervalue customers, thus reducing welfare even if output remains constant. Second-degree price discrimination does not have this effect. Hovenkamp and Hovenkamp (2010: 928929) ${ }^{7}$

The truth of this statement depends on what output is being measured. Hovenkamp and Hovenkamp focus on consumable output. It is straightforward to provide an example where consumable output falls and total welfare rises under second-degree price discrimination. ${ }^{8}$ Hovenkamp and Hovenkamp (2010: 928-29) further assert that second-degree discrimination generally benefits both total welfare and consumer welfare even without any output increase, and that this proposition directly applies to metering ties.

\footnotetext{
${ }^{7}$ See also Lambert (2011: 938) "second-degree price discrimination in the form of metering, unlike a third-degree price discrimination scheme, need not increase total output in order to enhance welfare."

${ }^{8}$ Take the case where there are 14 consumers, each of whom desires a printer for the sole purpose of making copies. One consumer wants to make ten copies, each worth $\$ 1$; another wants to make 100 copies, each worth $10 \phi$; and remaining 12 seek to make one copy worth $\$ 1.50$. If we assume that all costs are zero, then the profit-maximizing single price is $\$ 10$ for the printer, the firm earns $\$ 20$, and total welfare is also $\$ 20$. Under linear metering, the printer is given away for free, the profit-maximizing usage charge is $\$ 1$ per copy, the number of copies made falls from 110 to 22 , but profits rise to $\$ 22$, consumer welfare rises from 0 to $\$ 6$ and welfare rises to $\$ 28$.
} 
[For] second-degree price discrimination, ... the economic consensus is that most instances of it are probably welfare increasing... Further, they only harm consumer welfare in the most flagrant situations, and they often increase welfare even if output falls"9

However, the sources they cite for the claim that second-degree price discrimination generally increases consumer welfare claim are less than supportive. For example, Scherer and Ross (1990) conclude that all types of price discrimination redistribute consumer surplus to producers, while Motta (2004) writes second-degree price discrimination has effects similar to perfect price discrimination and can "appropriate all consumer surplus."

Nor is there an economic consensus on the welfare effect of second-degree price discrimination. Posner (2005) states that "in the case of second-degree price discrimination, ... the net effect on economic welfare is probably negative" though "in the setting of intellectual property the welfare effects even of second-degree price discrimination are likely often to be positive."

As we demonstrate below, the welfare result for third-degree price discrimination has a direct analogy for second-degree price discrimination in the case where there is a capital good whose usage requires a complementary consumable good, like using ink with a printer. In such markets second-degree price discrimination reduces total welfare unless it increases capital good output. Furthermore, with linear demand, second-degree price discrimination will not increase capital good output unless there is a category of buyers who would buy none of the product at the single profit-maximizing price but would with price discrimination.

Return to the case of a printer and toner cartridges where the price discrimination is done via metering. The firm has market power over the printer. Absent price discrimination, the firm sets a single price for the printer and allows customers to purchase toner cartridges in a competitive market. With metering, the firm requires the customer to only use its toner cartridges, which are sold at a price above cost. To test whether price discrimination necessarily decreases total welfare, we look at the output of printers, not toner cartridges. The output to measure is the sale of the capital good over which market power exists, not the tied product.

\footnotetext{
${ }^{9}$ Lambert (2010: 939 "Importantly, second-degree price discrimination via metering may increase consumer surplus even if it does not occasion an increase in total market output... There are good reasons to suppose ... that most instances of metering enhance consumer welfare."
} 
Metering may reduce the number of toner cartridges sold while increasing total welfare. But metering cannot increase total welfare without increasing the number of printers sold.

To test whether metering increases welfare using consumable output, there is analogous result that runs in the opposite direction, but one that is not as general. If metering increases consumable sales, then it increases total welfare, at least for the case where the capital good is costless and provided for free. The result is not as general because metering may lead to an inefficient number of capital good sales and thus the proof requires that the capital good be costless and given away. Moreover, if this test is passed, then sales of the capital good must also have increased.

Hovenkamp and Hovenkamp (2010) were referring to consumable output, not capital output. Because the connection between welfare and output turns so much on which output one is considering, we try to be extra clear about which product is which. The use of "tied" and "tying" product can easily lead to confusion. In our example, the printer is the tying product and the toner cartridge is the tied product. We think it is simpler terminology to think of the firm as having market power over a capital good, such as a printer or razor. The tied good is then the consumable product, such as the toner cartridge or the blade. Thus in our discussion below we will adopt this convention. A firm has market power over a capital good and there is no power over the consumable used with it. In this case, neither metering ties nor any form of seconddegree price discrimination can increase consumer welfare or total welfare without increasing capital good output.

\section{A. Any Price Discrimination (Including Metering Ties) Must Increase Capital Good Output to Increase Welfare}

We assume a market with a capital good whose usage requires a complementary consumable good. Neither the capital good (printer) nor the consumable good (ink) provide any utility on its own. The seller has market power over the capital good, and there is a competitive market for the consumable good, which is produced and sold at its marginal cost of $c_{1}$. For simplicity, we assume the capital good can be produced at a constant marginal cost of $\mathrm{c}_{0}$.

Without any metering tie or price discrimination, the seller charges a single price $p_{s}$ for its capital good and its customers are free to purchase the consumable good from the competitive 
market at price $c_{1}$. Thus, with single pricing, a customer who uses $n$ consumable units pays a total of $p_{s}+c_{1} n$.

A customer of type $\alpha$ will purchase the capital good if there is some $n$ for which the value $V_{\alpha}(n) \geq p_{s}+c_{1} n$, where $V_{\alpha}(n)$ is the value a customer of type $\alpha$ gets from using the capital good with $n$ consumable units. We assume customers are only interested in one unit of the capital good.

With a metering tie, the seller requires the consumers to purchase all of the consumables from it as a condition of buying the capital good. Thus, with a metering tie, the seller charges a price of $p_{m}$ to buy the capital good upfront and then a metering price of $m>c_{1}$ for each unit of the consumable good, so that a customer who uses $n$ units of the consumable pays a total of $p_{m}+$ $m n$. Metering ties thus require restraining buyers from purchasing the consumable from the competitive market. Here the customer of type $\alpha$ will purchase the capital good if there is some $n$ for which $V_{\alpha}(n) \geq p_{m}+m n .^{10}$

Although much of this paper focuses on such metering ties, the proof that follows is more general because it applies not only to metering ties but also to any form of second-degree price discrimination used when a seller has market power over a capital product but no market power over a consumable used with it.

Under metering, the price of the consumables is typically constant with volume, but it need not be. More generally, the seller might employ non-linear pricing for the consumables. To use a non-constant metering tie, a seller will have to be able to directly observe how many consumable units each buyer is buying and to prevent buyers from reselling consumables to each other. In that case, $m$ becomes the average price paid per consumable unit by a buyer who uses $n$ consumable units, which we will call $m(n)$ because it is a function of $n$. Taking into account the cost of the capital good, a customer who buys $n$ units of the consumable good pays a total of $p_{m}$ $+m(n) n$. The results that follow apply to any form of second-degree price discrimination done via non-linear pricing for the consumable good. ${ }^{11}$

Our results also apply when the metering or price discrimination is done without the use of a forced tie. For example, if the firm could attach a meter to the capital good and directly

\footnotetext{
${ }^{10}$ We follow convention and assume that a consumer who is indifferent will make a purchase.

11 In our model, there is only one good being consumed and so this limits the scope for second-degree price discrimination. For example, the firm cannot engage in bundling pricing across multiple goods.
} 
observe how often each buyer used it then sellers could directly charge per usage without a need to impose a metering tie that restrains purchases of the tied consumable. In such a case, the consumer would buy the consumable (toner) in the competitive market at price $c_{l}$ and then pay an additional per-unit toll of $m(n)-c_{1}$ to the firm. Equivalently, the firm's price of the capital good could vary based on usage of the consumable.

Because such direct observation is often not feasible, metering ties can be used to facilitate price discrimination that cannot otherwise be accomplished. Assessing the effects of direct price discrimination is important because the welfare effects are the same whether the metering is done directly or via a tied sale. Indeed, our results might suggest legal condemnation should also apply in the situations when direct price discrimination is used but fails to expand output of the capital good. ${ }^{12}$

We focus on situations where metering ties or other forms of price discrimination are profitable, by which we mean they strictly increase seller profits compared to charging a single profit-maximizing price. If they did not increase profits, then a seller would have no incentive to engage such conduct. Thus, all the cases where a seller would want to engage in metering ties and price discrimination will fall under our results. ${ }^{13}$

\section{Theorem 1: If a seller has market power over a capital good and there is no market power over a consumable used with it, then any profitable price discrimination (including a metering tie) cannot increase total welfare unless it increases total sales of the capital good.}

\footnotetext{
${ }^{12}$ Under U.S. law, unless such direct price discrimination involves some other form of agreement that restrains trade, it would typically be legal because it would not usually violate the Robinson-Patman Act, which requires either below-cost predatory pricing that excludes the seller's rivals or price differences that distort competition among buyers who themselves are businesses that sell in some downstream market. Even though the effects of metering ties and direct price discrimination are similar, the law might rationally treat them differently to reflect the fact that direct price discrimination is often unfeasible (and thus less often problematic), can often be possible without market power, and is generally more difficult to regulate in an administrable fashion because setting prices (unlike tying) is generally unavoidable.

${ }^{13}$ Because we assume the best case for metering ties by assuming they (and other forms of price discrimination) are costless, a seller with market power would always be able to do at least as well with metering ties as with a single price: it could charge $\mathrm{p}_{\mathrm{s}}$ upfront and $\mathrm{c}_{1}$ as the metering price thus replicating the single profit-maximizing price result. While this is generally not profit-maximizing, there are some exceptions. For example, if there is only one consumer type (so all consumers share the same exact valuations and usage rates), then a single price can extract all consumer surplus, so there is no need to employ any form of price discrimination.
} 
Theorem 2: If a seller has market power over a capital good and there is no market power over a consumable used with it, then any profitable price discrimination (including a metering tie) always reduces consumer welfare unless it increases total sales of the capital good.

Theorem 3: Unless it increases total sales of the capital good, profitable price discrimination always reduces total welfare other than in the special case where the price discrimination leaves total welfare unchanged if it both (i) does not change any of the customers who buy and (ii) does not reduce consumable usage by those who valued that usage above the consumable cost.

Proof of Theorem 1: We first observe that for all consumers-those who purchase the capital good and those who do not- the total potential welfare from that consumer is maximized when the consumable is sold at marginal cost. This is because conditional on buying the capital good, the consumer will then purchase the amount of the consumable that maximizes $V_{\alpha}(n)-c_{1} n$. Here, consumer utility and total welfare coincide. Thus consumers who buy the capital good choose the efficient amount of consumables and maximize total welfare from their purchase. Even consumers who do not purchase are maximizing their potential contribution to total welfare. They may not purchase because the capital good price is too high, but had they purchased they would have contributed as much as possible to total welfare.

With single pricing, the price for the capital good is $\mathrm{p}_{\mathrm{s}}$, so all customers who bought the capital good must have valued it at $p_{s}$ or greater, and thus each contributes $p_{s}-c_{0}$ or more to total welfare. ${ }^{14}$ All customers who did not purchase the capital good with single pricing must have valued it at less than $p_{s}$, and thus each necessarily would have added something less than $p_{s}-c_{0}$ to total welfare if they had bought. By the argument above, they could not have contributed any more under any other pricing scheme.

If price discrimination leaves capital good output unchanged but changes the set of customers who buy, it must replace one or more of the original customers with an equal number of new customers. That replacement necessarily strictly lowers total welfare because the lost

\footnotetext{
${ }^{14}$ Note that $p_{s}-c_{0} \geq 0$ as the seller is maximizing profits and would lose money at any price below $c_{0}$.
} 
original customers contributed more to total welfare than the new customers can add. If price discrimination reduces output of the capital good, then it must further reduce total welfare because it also loses one or more of the original customers without replacing them. Therefore price discrimination cannot raise total welfare without also raising capital good output.

Proof of Theorem 2: From Theorem 1, we know that total welfare cannot increase unless capital good sales also rise. Total welfare is the sum of profits and consumer surplus. Therefore, if price discrimination leaves total welfare unchanged but increases profits, it must reduce consumer surplus. If price discrimination lowers total welfare, then profitable price discrimination must reduce consumer surplus even further.

Proof of Theorem 3: Here we want to know when total welfare can remain constant as opposed to strictly falling when profitable price discrimination is implemented but capital good sales do not rise. We know from the proof of Theorem 1, that total welfare will fall if any of the consumers under the single price rule are replaced by some new consumers under price discrimination. If price discrimination leaves unchanged both capital good output and the customers who buy, but raises the consumable price in a way that reduces usage by customers who valued that usage above the consumable cost, then it necessarily reduces total welfare. In the special case where price discrimination leaves unchanged capital good output, customer identity, and their consumable usage, then it leaves total welfare unchanged. It is also possible for consumers to cut back their purchases of consumables for which they were indifferent. There would be no loss to total welfare if a consumer who valued a unit at $c_{l}$ no longer purchases that last unit because the metering price is above $c_{1}{ }^{15}$

Remarks. There are several points to note about these theorems. First, these theorems are designed to be the analog of results proven in earlier literature (Robinson (1969), Varian (1985), Schmalensee 1981) for third-degree price discrimination. Indeed, the structure of the proof builds

\footnotetext{
${ }^{15}$ The following is an example where metering will increase profits without lowering total welfare. There are two consumers. One values the first unit of consumables at $\$ 3$, a second unit at $\$ 2$, and a third unit at $\$ 1$; he has no value for additional units. The second consumer values the first unit of consumables at $\$ 3$ and has no value for additional units. Marginal costs are $\$ 1 /$ unit of consumable and zero for the capital good. Under a single price, the seller would charge $\$ 2$ for the capital good. Both consumers would purchase the capital good and the seller would earn $\$ 4$. With price discrimination, the seller could charge $\$ 1$ for the capital good and $\$ 2 /$ unit for the consumables. Both consumers would still purchase the capital good, but the seller's profits would rise to $\$ 5$ ( $\$ 2$ from sales of the capital good plus $\$ 3$ from sales of the consumables). Note that the first consumer cut back one unit of consumable purchases, but this had no effect on welfare as the valuation was equal to cost. Any other change in consumption would strictly lower total welfare.
} 
on a textbook example in Tirole (1998) and is almost a direct translation of the third-degree price discrimination proof in Schwartz (1990).

These theorems extend those prior results to any price discrimination-including metering ties and second-degree price discrimination - that is used when a seller has market power over a capital good but there is no power over the consumable used with it. ${ }^{16}$

To be sure, a single-pricing firm with market power over a capital good is inefficient in that it prices too high and thereby cuts off demand from customers for whom it would be efficient to purchase the good. But a single-pricing seller is inefficient in a maximally efficient way - the customers excluded from the market are those who have the lowest value from the good. The single-pricing firm sells the consumable in an efficient manner so as to extract the greatest possible price upfront. A price-discriminating seller with market power cannot beat the efficiency of a single-pricing seller for the consumers who were served in the market. Its only hope for improving efficiency is to expand the set of consumers who are served.

Second, the theorems do not show that price discrimination can never increase consumer welfare or total welfare. The theorems show only that in this situation it cannot do so unless it increases output of the capital good. The same proposition does not apply to consumable output because profitable price discrimination in this situation might sometimes increase consumer welfare even though it decreases consumable output. The change in capital good output provides a useful test to determine if a welfare increase is possible. Below, we present a model specification in which profitable price discrimination via metering ties fails to increase output; therefore, by Theorem 2, it must strictly lower consumer welfare and we will show that Theorem 3 also applies so that it also strictly lowers total welfare in this case. Thus, a seller that wanted to demonstrate that its metering tie did not harm welfare would, as a necessary condition, be required to show that its price discrimination resulted in a strict increase in the quantity sold of the capital good.

A More Limited Converse Result for Consumable Output. One can also derive a more limited converse result based on the observation that although a seller that uses a metering tie elevates the consumable price in a way that limits consumable sales, the consumables that are

\footnotetext{
16 Because our model assumes this situation, it does not extend to other situations where second-degree price discrimination might be used, such as when a seller has market power over the consumable or when the tied and tying goods are not used together and have separate demand.
} 
sold are allocated efficiently. That is, a tying firm that charges a price $m>c_{1}$ for the consumables restricts consumable sales, but sells those consumables to the consumers who value them the most. In other words, if with a metering tie total consumable sales are 80 units, then those 80 units are delivered to the consumers who value them the most.

It might seem that this observation produces the converse result - that metering ties increase total welfare whenever they increase output of the consumable good. But this is not true. The reason is that metering is not efficient in terms of its allocation of the capital good. Too many consumers who have a high unit value for low usage will be brought into the market ${ }^{17}$ while others consumers with high usage and low unit value will be excluded. But this is only an issue if the capital good is costly. If the capital good can be produced at zero cost and the metering tie provides the capital good for free, then there is no potential inefficient allocation of the capital good as everyone can be given the good. All that matters is the allocation of the consumable good which metering does efficiently.

With costless and free capital goods, we establish the converse result with the addition of the standard assumption of declining marginal utility.

\section{Theorem 4: If (i) the capital good is costless $\left(c_{0}=0\right)$, (ii) the price with a profitable metering tie is 0 for the capital good, and (iii) the marginal value of the consumable is weakly decreasing for each consumer type, then a metering tie will increase total welfare if it increases total sales of the consumable good.}

Proof of Theorem 4: The proof of this result follows the same argument as in Theorem 1, except from the opposite direction. With a metering tie, the price for the consumable is $m$, and $m$ $>c_{1}$ as otherwise the metering would not be profitable. All consumable units purchased must be valued at or above $m$ (given declining marginal utility), and each consumable sale contributes $m$ $-c_{1}$ or more to total welfare. Because the cost of the capital good is zero, the only customers who would not take the capital good are those who value the consumable at less than $m$. Thus, any consumer who does not buy the consumable with a metering tie must value all consumable

\footnotetext{
${ }^{17}$ Because of the high profits on toner cartridges, laser printers are almost free, especially as they come with a starter cartridge. The low price of laser printers has resulted in three of them being scattered around one of the author's households; absent metering, the printer would be more expensive and there would be only one printer used three times as much.
} 
units at less than $m$, and each would necessarily have added something less than $m-c_{1}$ per consumable unit if they had bought consumables. If a metering tie increases the total consumables sold it must increase total welfare because any reallocation of consumable output from original to new customers cannot decrease total welfare and any additional consumable output adds to total welfare.

Remark 1. Theorem 4 does not apply to consumer welfare. This is because such a metering tie might increase profits by more than it increases total welfare, in which case it would lower consumer welfare.

Remark 2: In the case where $c_{0}>0$, consumable sales can increase while total welfare falls. The intuition for how this is possible is as follows. A firm that meters is willing to sacrifice some customers who add a great deal to total welfare but very little to profits. This is done in order to extract more of the consumer surplus from the remaining customers. While this would by itself reduce consumable sales, it is also possible that the metering brings in some additional consumers and thereby some additional consumable sales, but due to the high cost of the capital good these additional sales do not add much to total welfare. Thus total welfare falls due to the exclusion of some consumers who were previously obtaining a large amount of consumer surplus.

An example shows how this is possible. There are 30 consumers in the market. Their valuation for using consumables with the capital good is as follows:

Consumer 1 values 100 units each at 0.5

Consumers 2 and 3 value 50 units each at 0.5

Consumer 4 values 100 units each at 0.25

Consumers $5-30$ value 4 units each at 0.5

The cost of the consumable is 0 and the cost of the capital good is 1.9.

The profit-maximizing single price of the capital good is 25 . Consumers $1-4$ will purchase. Total profits are $100-4 * 1.9=92.4$. Total welfare is 117.4 (because consumer 1 has 25 units of consumer surplus and consumers $2-4$ have none).

With a metering tie, the profit-maximizing prices are 0 for the capital good plus 0.5 for the consumable. In that case, consumers $1-3$ and 5-30 all purchase. Total profits are $100-3 * 1.9$ $+26 *(2-1.9)=94.3+2.6=96.9$, and the firm will find it profitable to adopt a metering tie. 
Total welfare is also 96.9 (because consumer surplus drops to zero), and thus the metering tie lowers total welfare.

In this example, the metering tie raises consumable sales from 300 to 304. Thus, this metering tie is more profitable and has higher consumable sales, but lowers total welfare. The reason for the reduction is that the metering firm was willing to sacrifice the highly efficient sales of 100 units to customer 4 in order to extract more surplus from consumer 1 . While those unit sales were made up via consumers 5-30, once one takes the capital cost into account, the new 104 units of consumables that came into the market brought a very low welfare contribution, namely $0.1 / 4=0.025$ per unit.

What Theorem 4 shows is that, just as single-pricing is efficient in allocating the capital good, a metering tie is efficient in allocating the consumable goods, subject to the constraint that all consumers get access to the capital good with the metering tie. But remark 2 shows that constraint has significant bite. It limits the result to the case of where the capital goods have zero cost and the metering seller maximizes profits by earning all its revenue on the consumable good. This limit means Theorem 4 has less practical relevance than Theorems 1, 2 and 3. In a typical metering tie, the capital good is something like a printer and the consumable is something like ink or paper. Thus, typically the variable cost of the capital good is high and the variable cost of the consumable is low. Once the capital good has positive costs and is priced above zero with a metering tie, there may be consumers who value consumables above $m$ but do not buy with a metering tie because their consumer surplus after paying $m$ per unit of the consumable might not suffice to cover the capital good price. Those same customers might have bought without a metering tie if their consumer surplus after paying $c_{1}$ per consumable unit exceeded the capital good price without a metering tie. The metering tie thus can no longer guarantee a more efficient allocation of consumables once capital goods have a positive cost.

The assumption of zero cost for the capital good also biases the scale in favor of metering ties. This is because metering ties bring in more low-demand consumers and so require more capital goods. If these capital goods are costly to produce, then this move will be less advantageous to welfare.

The combination of Theorems 3 and 4 enable us to draw some interesting conclusions. Consider the table below which compares the change in output in both capital goods and 
consumables in going from single pricing to metering ties, in the special case where the capital good has zero cost and is provided for free with the metering tie.

\begin{tabular}{|l|l|l|}
\hline & Capital Good Sales & Consumable Sales \\
\hline Case 1 & Higher & Higher \\
\hline Case 2 & Higher & Lower \\
\hline Case 3 & Lower & Higher \\
\hline Case 4 & Lower & Lower \\
\hline
\end{tabular}

In Case 1, the metering tie increases both capital and consumable good consumption. In that case, we know from Theorem 4 that the increase in consumable sales means that the metering tie will increase total welfare. There is no conflict with Theorem 1 because capital good output also rose.

Case 4 is the other end of the spectrum. Here, the metering tie reduces both capital and consumable good consumption. By Theorems 1 and 3, we know that the metering tie must reduce total welfare. There is no conflict with Theorem 4 because consumable output declined.

Case 3 seems to present a paradox. On one hand, because the metering tie reduces capital good sales, Theorems 1 and 3 mean that total welfare must have gone down. On the other hand, because consumable consumption has gone up, Theorem 4 means that total welfare must have risen. What this paradox tells us then is that Case 3 is not possible. If the capital good is costless and a metering tie gives away the capital good, it cannot reduce capital good sales while increasing consumable sales.

Case 2 is the ambiguous case. The higher capital good sales means that the metering tie might increase total welfare under Theorem 1, but the lower consumable sales means that an increase in total welfare is not guaranteed by Theorem 4. Thus, such a metering tie could lead to an increase or decrease in total welfare (or consumer welfare), depending on the distribution of customer types. 


\section{B. Metering Ties Can Fail to Increase Output and Thus Lower Welfare}

Although the general proof shows that metering ties must increase capital good output in order to increase welfare, that result would be less interesting if metering ties always increased capital good output. In this section, we provide a simple model in which profitable metering ties fail to increase capital good output and thus reduce both consumer and total welfare.

Market Assumptions: (i) We assume that both the capital good and consumable can be produced at a constant marginal cost, $\mathrm{c}_{0}$ for the capital good and $\mathrm{c}_{1}$ for the consumable. (ii) The seller has market power over the capital good, but the consumable good is available on a competitive market at its marginal cost. (iii) If the seller engages in single pricing, it sells the capital good at the profit-maximizing price and customers use as many consumable units as they want at a price of $c_{1}$. If the seller uses a metering tie, it sells the capital good and consumable goods at profit-maximizing prices under the condition that buyers purchase all consumables from it. (iv) A customer of type $(a, n)$ wants to use $n$ units of the consumable and values each unit at $a$. (v) The value of $a$ is distributed uniformly over $[0,1]$ and $n$ is distributed according to the nonatomic density function $g(n)$, with cumulative distribution $G(n)$. (vi) Finally, we assume there are some customers for whom $n\left(1-c_{1}\right)-c_{0}>0$.

Part (vi) of the Market Assumptions ensures that there are some customers in the market that can be profitably served. In other words, costs are not so high that the capital good would never be produced. While we have assumed the distribution of $n$ is not all concentrated on a single type, we are not constraining the distribution to have some specific form such as a uniform, normal, or lognormal distribution.

Metering Tie. We look at the case of metering with a two-part pricing scheme. The seller charges a price $p_{m}$ for the capital good plus a price $m$ per copy. For ease of notation, we will drop the subscripts on $p$ when the context is clear.

To find the profit-maximizing $(p, m)$, we imagine that the seller knows each customer's usage rate $n$ and can give prices tailored to each customer group with a particular usage rate. The customer with demand $n$ will purchase the capital good if and only if

$$
n(a-m) \geq p \text { or } a \geq \frac{p}{n}+m \text { which has probability }\left[1-m-\frac{p}{n}\right]
$$

Note that unless $n \geq p /(1-m)$, the probability of a purchase is zero. Since the seller can charge customized prices to each $n$ type it would choose $(p, m)$ to maximize 


$$
\left(p-c_{0}+n\left(m-c_{1}\right)\right) *\left[1-m-\frac{p}{n}\right] .
$$

Profits are maximized when $p+m n=\left(c_{0}+n c_{1}+n\right) / 2.18$ This can be accomplished by setting $p=c_{0} / 2$ and $m=\left(1+c_{1}\right) / 2$. The solution for $p+m n$ is unique, even if the $(p, m)$ combination is not. However, this is the only $(p, m)$ combination that maximizes profits without requiring the seller to set a different capital good price $p$ for each $n$-type customer. ${ }^{19}$

Thus, while we assumed that the seller had knowledge of $n$, such knowledge is not required as the customized pricing does not depend on $n$. The profit-maximizing prices with a metering tie are half the cost of the capital good and the halfway point between the marginal cost and maximum valuation on the consumable. It is worth noting that if the capital good has zero cost, then $p=0$ and the profit-maximizing metering scheme can rely entirely on a metering price.

Single Pricing. With single pricing, the seller sells the capital good alone for a uniform price of $p$. A customer of type $(a, n)$ will purchase the machine if and only if

$$
n\left(a-c_{1}\right) \geq p \text { or } a \geq \frac{p}{n}+c_{1} \text { which has probability }\left[1-c_{1}-\frac{p}{n}\right] .
$$

Note that unless $n>p /\left(1-c_{1}\right)$, the probability of a purchase by customers of type $n$ is zero. That is because the highest valuation per usage is 1 , and thus the highest valuation any customer of type $n$ can put on a capital good is $n\left(1-c_{1}\right)$.

The price is chosen to maximize profits where

$$
\text { Profits }=\int_{p /\left(1-c_{1}\right)}^{\infty}\left(p-c_{0}\right)\left[1-c_{1}-\frac{p}{n}\right] g(n) d n \text {. }
$$

Profits are maximized at

$$
\frac{d \text { Profits }}{d p}=0=>\int_{p /\left(1-c_{1}\right)}^{\infty}\left[1-c_{1}-\frac{2 p-c_{0}}{n}\right] g(n) d n=0 .
$$

The seller's profit-maximizing single price $p^{*}$ is thus the solution to (3)

\footnotetext{
${ }^{18}$ To get this result, set $z=p+m n$ in the profit equation. The first derivative is zero when $z=\left(c_{0}+n c_{1}+n\right) / 2$, which is a maximum because the second derivative is negative.

${ }^{19}$ For example, other $(p, m)$ combinations that satisfy this equation are $p=\left(c_{0}+n c_{1}+n\right) / 2$ coupled with $m=0$ or $p=\left(c_{0}-n c_{1}+n\right) / 2$ coupled with $m=c_{1}$, but those alternative solutions would require the seller to be able to set a different value of $p$ for each $n$-type customer.
} 


$$
p^{*}=\frac{c_{0}}{2}+\frac{\frac{1}{2}\left(1-c_{1}\right)}{\int_{p^{*} /\left(1-c_{1}\right)}^{\infty} \frac{g(n)}{n} \frac{g\left(p^{*} /\left(1-c_{1}\right)\right)}{1-G}}
$$

The expression for $p^{*}$ has some parallels to pricing under metering. In both cases, the consumer pays half the cost of the capital good, $\frac{c_{0}}{2}$. Under metering, each consumer pays an additional $\frac{1}{2}\left(1+c_{1}\right) n$ for the consumables, but since the firm has to pay the cost, its net profit on the consumables is $\frac{1}{2}\left(1-c_{1}\right) n$. With single pricing, each customer who buys the capital good pays an additional $\frac{1}{2}\left(1-c_{1}\right) H$, where $\mathrm{H}$ is the harmonic mean of the value of $n$ among those who buy. Thus the pricing is similar, in that single-price firm's price for the capital good in effect include the same mark up on consumable usage, but instead of being multiplied by each customer's actual usage with the tie, it is multiplied against the harmonic average usage of all the customers who buy without the tie.

\section{Theorem 5: Under our Market Assumptions, a metering tie always increases profits for any distribution of usage rates.}

Proof of Theorem 5: Under metering, the seller could perfectly replicate the profits under single pricing by choosing the combination of $p=p^{*}$ and $m=c_{1}$. In this case, the metering firm sells (or resells) the consumable good at cost and makes all of its profits on the single upfront price. The fact that the metering firm does not pick this price combination means that it can earn higher profits by choosing $p=c_{0} / 2$ and $m=\left(1+c_{1}\right) / 2$.

As shown above, profits under metering depend on $p$ and $m$ only via $p+n m$. Because single pricing is a special case of (non-profit-maximizing) metering, this proposition is equally true for it. Thus the profits with single pricing and profit-maximizing metering could coincide only if $p+n m$ has the same value for each, which is when:

$$
p^{*}+c_{1} n=\frac{c_{0}}{2}+\frac{1+c_{1}}{2} n \text { or } n=\frac{2 p^{*}-c_{0}}{1-c_{1}} .
$$

Since metering profits are strictly concave in $p+m n$ (over the range of $a$ and $n$ where demand is positive), profits must be strictly higher with profit-maximizing metering for all but the one $n$ where they coincide. Thus integrating over $n$, profits could be equal only if all consumers who buy have the same value of $n$. But that would contradict our Market Assumption that $g(n)$ has no mass points. 
The importance of Theorem 5 is that it shows that firms with market power will want to engage in metering if given the opportunity.

It is also the case that with our Market Assumptions, metering never reduces sales of the capital good no matter what the distribution of usage rates.

\section{Lemma 1: Under our Market Assumptions, metering ties will either increase capital good sales or leave them unchanged for any distribution of usage rates.}

Proof: With a metering tie, a consumer with preferences $(a, n)$ will purchase if

$$
n\left(a-\frac{1+c_{1}}{2}\right) \geq \frac{c_{0}}{2} \text { or } a \geq \frac{1+c_{1}}{2}+\frac{c_{0}}{2 n} \text {. }
$$

Thus demand for the capital good is

$$
\frac{1}{2} \int_{c_{0} /\left(1-c_{1}\right)}^{\infty}\left[1-c_{1}-\frac{c_{0}}{n}\right] g(n) d n
$$

Under single pricing, total Capital Demand is

$$
\int_{p^{*} /\left(1-c_{1}\right)}^{\infty}\left[1-c_{1}-\frac{p^{*}}{n}\right] g(n)=\frac{1}{2} \int_{p^{*} /\left(1-c_{1}\right)}^{\infty}\left[1-c_{1}-\frac{c_{0}}{n}\right] g(n) d n,
$$

where the second equality follows substitution of equation (2).

The only difference in the total capital demands with metering versus single pricing is the starting point of the integral. In the case of metering, the integral starts at $c_{0} /\left(1-c_{1}\right)$, and so the value of the integrand starts at zero. In the case of single pricing the integral starts at $p^{*} /(1-$ $\left.c_{1}\right)$. Since profits are positive, we know that $p^{*}>c_{0}$ and so

$$
\int_{p^{*} /\left(1-c_{1}\right)}^{\infty}\left(1-c_{1}-\frac{c_{0}}{n}\right) g(n) d n \leq \int_{c_{0} /\left(1-c_{1}\right)}^{\infty}\left[1-c_{1}-\frac{c_{0}}{n}\right] g(n) d n .
$$

Demand for the capital good will be strictly greater under metering unless $g(n)$ is zero for $c_{0} /\left(1-c_{1}\right) \leq n \leq p^{*} /\left(1-c_{1}\right)$.

Note that in the special case where $c_{0}=c_{1}=0$, capital good demand under metering is $1 / 2$ and is $1 / 2\left[1-G\left(p^{*}\right)\right]$ under single pricing.

The next theorem uses the condition that each customer group of usage rate $n$ has at least one customer who buys the capital good with single pricing. This condition means that the entire body of the distribution of $n$ lies above $p^{*} /\left(1-c_{1}\right)$, that is $G\left(p^{*} /\left(1-c_{1}\right)\right)=0$. For example, suppose $c_{0}=c_{1}=0$ and the distribution of $n$ were uniform over [50,100]. Then the harmonic mean would be $50 /[\ln 100-\ln 50]=72$, and the profit-maximizing single price would be half the 
harmonic mean, or 36; here the condition would be satisfied because this is less than the minimum $n$ of 50. Indeed, for any uniform distribution of $n$ ranging from $[\underline{n}, 100]$ this condition is satisfied as long as $\underline{n} \geq 28.5$.

Theorem 6. Under our Market Assumptions, if each customer group of usage rate $n$ has at least one customer type who buys the capital good with single pricing, then profitmaximizing metering ties will reduce both total welfare and consumer welfare.

Proof of Theorem 6. Given the condition that $G\left(p^{*} /\left(1-c_{1}\right)\right)=0$, Lemma 1 shows that total capital good output with single pricing is exactly the same as with a metering tie. This is because there are no $n$-type customers with $c_{0} /\left(1-c_{1}\right) \leq n \leq p^{*} /\left(1-c_{1}\right)$.

By Theorem 5, profit with a metering tie must be strictly higher than under uniform pricing. Since capital good output is unchanged and profits are higher, it follows directly from Theorem 2 that consumer welfare must fall. If we can show that some new consumers replace existing customers, then by Theorem 3 total welfare must also strictly fall because capital good output has remained constant.

To show that Theorem 3 implies that the metering tie affirmatively reduces total welfare, we only need to show that there is some customer of type $(a, n)$ that buys with the metering tie that would not buy with single pricing.

Under single pricing, the indifferent consumer is

$$
a=\frac{p^{*}}{n}+c_{1}
$$

Under metering, the indifferent consumer is

$$
a=\frac{c_{0}}{2 n}+\frac{1+c_{1}}{2}
$$

As $\mathrm{c}_{1}<1$, the indifferent consumer can only be the same for one value of $n \cdot{ }^{20}$ Thus there must be a different set of consumers for different values of $n$. The exception would be if demand were positive only at a single value of $n$. But that would contradict the assumption that profits are strictly positive, which requires a positive interval of demand as the distribution of $n$ has no mass points.

\footnotetext{
${ }^{20}$ The indifferent consumer is the same when $n=\frac{2 p^{*}-c_{0}}{1-c_{1}}$, which is the one value of $n$ for which profits are the same under metering and single pricing.
} 
Remarks. In this simple case, we find that metering ties produce the same total sales of the capital good but more of those sales go to consumers with small values of $n$ and are thus the allocation is less efficient. This example shows that there should be no presumption that metering ties or any form of price discrimination will strictly increase sales of the capital good.

Profit-maximizing pricing by a seller with market power will inefficiently reduce the supply of the capital good, but will allocate those goods as efficiently as possible. Metering will inefficiently reduce the supply of the tied good, but will allocate those goods as efficiently as possible. If the capital good output does not increase under metering, then there is only increased inefficiency in the allocation of the capital good. Thus, sales of the capital good must strictly increase to have a chance to offset this inefficiency.

The condition that each customer group of usage rate $n$ buys at least some of the capital good with single pricing is similar to the assumptions used by Robinson (1969), Schmalensee (1981), and Varian (1985). It says that when this assumption holds, there is some consumer of each $n$ type that is in the market. Thus when the seller raises its price it will lose customers from each $n$ type. If this assumption were not true, then raising price would be less costly as once all of an $n$-type are driven from the market there is no longer additional loss from raising price to that type.

Our example parallels the linear demand assumption used by Robinson (1969), although it is not the linear demand typically seen. Normally we think of heterogeneity in demand as a series of parallel demand curves with different intercepts. Here we have both different slopes and different intercepts. For example, the demand from customers with $n=10$ starts at 1 (when the price is 0 all customers buy the capital good) and falls to 0 when the price hits 10 . The condition in Theorem 6 means that that the consumer with the highest $a$ type $(a=1)$ and the lowest $n$ type must buy with single pricing. With linear demand from each group, metering ties cannot expand output if they do not expand the customer groups that buy. 


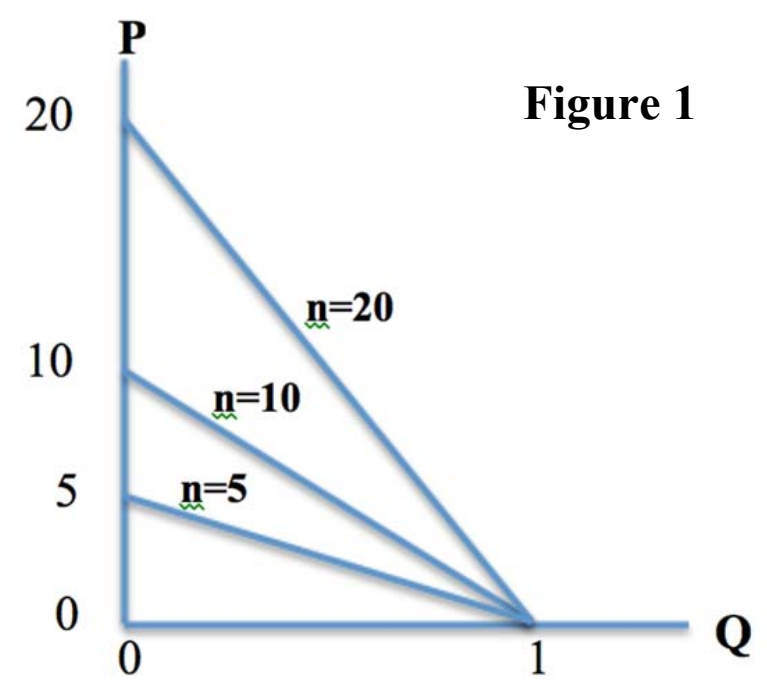

We know that it is possible that metering can increase or decrease consumer welfare and total welfare. In the next section, we show that the effects can be signed given further distributional assumptions regarding the demand for consumables. Here, we end this section with a result that shows that a small reduction in metering will always improve both consumer and total welfare.

\section{Theorem 7: Under our Market Assumptions, a small reduction in metering leads to an increase in both consumer welfare and total welfare.}

Proof: See Mathematical Appendix

It is useful to first explain how this result differs from the typical result on monopoly power. Consider a monopolist restricted to a single price, $p_{s}$. If we somehow were to force the monopolist to lower its price form the monopoly level this would clearly be a win for consumers (who gain from lower prices). From the monopolist's perspective, since $p_{s}$ was maximizing profits, there would be no first-order loss to profits. Since we have a first-order gain to consumers and no first-order loss to the firm, a small reduction in price from the monopoly level will increase both consumer and total welfare.

In our case, the result is not so straightforward. Here we are considering the effect when a monopolist lowers $m$ from its profit-maximizing level. This is clearly good for consumers (who once again prefer lower prices) and has no first-order impact on profits (as $\mathrm{m}$ was chosen optimally). The complication is that as the monopolist lowers $m$, it raises the corresponding fixed 
price, $\mathrm{p}_{m}$. Changing the fixed price also has no first-order impact on profits (as $p_{m}$ was chosen to maximize profits), but it does hurt consumers. Thus the question: Is the reduction in the metering charge $m$ more or less offset by the increase in $p_{m}$ ? Theorem 7 demonstrates that the increase in the upfront price is not enough to offset the gains from a lower metering charge.

\section{LOGNORMAL BUYER USAGE DISTRIBUTION}

Theorems 1-4 are general in that they apply to any distribution of buyer usage rates (although they employ a uniform distribution of per-unit valuations). But the total welfare result of theorem 6 requires the additional assumption that the single profit-maximizing price leaves some of each usage type in the market. This is a sufficient condition for metering ties to reduce total welfare, but is not a necessary condition. To see what happens when a single price excludes some buyer types, we consider the results for some plausible distributions of buyer usage rates. Each of us has, in separate prior works, considered the case with zero costs and a uniform distribution of both buyer usage rates and buyer valuation per usage; Elhauge (2009) and Nalebuff (2009). In this case, metering is always profitable and always reduces consumer surplus; see corollary to Theorem 8. The effect on total surplus depends on the ratio of the maximum usage rate $H$ to the minimum usage $L$. If $H / L$ is below 4.64 then total welfare is higher under single pricing and if $H / L$ is above 4.64 then total welfare is higher under metering. ${ }^{21}$ This is in line with our intuition. The advantage of metering arises when there is greater dispersion in usage and some of the market is left unserved with the single price. Thus when dispersion, here $\mathrm{H} / \mathrm{L}$, is large enough, then metering leads to greater efficiency.

Although our assumption of a uniform distribution of buyer usage rates in prior work simplifies the math, it is unrealistic. In most things in life, extreme preferences are less common than moderate preferences. There might exist some buyers who would use a printer only once at competitive ink prices, and other buyers who would use it a million times, but it would be surprising if such extreme buyers were just as likely as buyers who would use their printer more moderately.

\footnotetext{
${ }^{21}$ See Nalebuff (2009: Theorem 3). In this theorem, $\mathrm{L}=1$, but the results scale so that all that matters is the ratio of $\mathrm{H}$ to $L$. The theorem uses the ratio of 4.58 , but that is slightly low due to earlier rounding. Note also that if $L=0$, then $H / L>4.64$ so that metering raises welfare. But this is less relevant in that machines cost money to make and thus buy, so no one is likely to buy a machine and only use it once or a few times.
} 
Here we assume a lognormal distribution of buyer usage rates. A lognormal distribution has two advantages. Compared to a normal distribution, it avoids the need to truncate the distribution to take into account the fact that buyers cannot desire a negative number of tied units. And it allows for a closed-form solution for consumer surplus, profits, and total welfare.

Consumer welfare. The results under a consumer welfare standard are straightforward: When capital costs are zero, metering ties always lower consumer welfare with a lognormal distribution.

Theorem 8: Under our Market Assumptions with $c_{0}=0$, metering ties always lower consumer surplus for any lognormal distribution of buyer usage rates.

Proof: See Mathematical Appendix

Corollary: Under our Market Assumptions with $\mathbf{c}_{0}=0$, metering ties always lower consumer surplus for any uniform distribution of buyer usage rates.

Proof: See Mathematical Appendix

Implications. Assuming a lognormal distribution of buyer usage rates, metering ties are always profitable (by Theorem 5) and always reduce consumer welfare. Under the consumer welfare standard that we believe is legally applicable, this proof supports condemning metering ties unless defendants can show that Theorem 8 or its Corollary do not apply. They could do so by demonstrating: (1) productive efficiencies that are passed on enough to offset the consumer welfare harm; (2) that the Market Assumptions do not apply; (3) that capital good costs make an increase in consumer welfare likely; ${ }^{22}$ or (4) that some other more relevant distribution of buyer usage rates leads to an increase in consumer welfare under metering.

Theorem 9. Under our Market Assumptions with $c_{0}=0$ and a lognormal distribution of usage rates $n$, where with $\mu$ and $\sigma$ are the mean and standard deviation of the natural log of $n$, metering ties will lower total welfare for any $\sigma$ below 0.78 .

Proof: See Mathematical Appendix

\footnotetext{
${ }^{22}$ Positive capital good costs may make an increase in consumer welfare less likely because a precondition for metering to increase consumer welfare is that capital good output increases and this is now costly.
} 
This result is in line with our intuition and prior results from the uniform case. Metering does well when there is great variability in the quantity demanded. Indeed, if all customers had the same unit valuation and differed only in the quantity demanded then metering would achieve perfect price discrimination and maximize total welfare. Thus when the dispersion in quantity desired becomes large enough, specifically when $\sigma$ is above 0.78 , then metering becomes more efficient in the sense that it increases total welfare compared to single pricing.

Theorem 9 assumes no profit dissipation and no productive efficiencies from tying. If there were profit dissipation, then metering ties would reduce total welfare even if the standard deviation were higher than 0.78 . Let $d$ represent the fraction of incremental profits created by metering that are dissipated. If $d=10 \%$, then single pricing leads to higher total surplus for $\sigma$ below $1.03 .^{23}$ If $d=25 \%$, then single pricing leads to higher surplus for $\sigma$ below 1.74 . And if $d=33 \%$, then single pricing leads to higher surplus for $\sigma$ below 2.65 . Conversely, if there were productive efficiencies, then those efficiencies might (if large enough) offset the total welfare harm from metering ties.

The lognormal distribution provides an intuition for how our earlier results generalize. We know from Theorem 6 that if some members of all $n$ types are served in the market by a single-pricing seller with market power, then metering will always lower total welfare. If some types are completely excluded from the market with single pricing, that creates an opportunity for metering to expand sales of the capital good to the low- $n$ types and improve welfare. Under a lognormal distribution, consumers with the lowest values of $n$ will be entirely excluded by single pricing. For the case of $\sigma=0.78$, we find that $27 \%$ of customer types, that is the $27 \%$ lowest values of $n$, will not make any purchases. ${ }^{24}$ Thus, even if single pricing excludes a significant share of low-usage consumers, it can still lead to higher total welfare than metering ties.

It might help to visualize the distributions where metering ties do and do not harm total welfare. Figure 2 illustrates a range of distributions where metering ties raise or lower total welfare. With zero profit dissipation, the critical density curve where welfare is unchanged is at $\sigma$

\footnotetext{
${ }^{23}$ This result and the two other examples that follow come from a corollary in the appendix that extends Theorem 8 to take into account profit dissipation.

${ }^{24}$ The largest value of $\sigma$ for which single pricing is more efficient than metering is $\sigma=0.78$, which leads to $\mathrm{E}[n]=$ 1.36. The chance $n$ falls below $p$ is $\Phi\left(\frac{\ln (p)}{\sigma}\right)$. At $\sigma=0.78, p$ is $0.62, \ln (p) \approx-0.47$, and $\ln (p) / \sigma=-0.61$. Thus, the percentage of the distribution when $n<p$ is $\Phi(-0.61)=27 \%$.
} 
$=0.78$. With greater dispersion, metering raises total welfare and with less dispersion metering lowers total welfare. As one can see, the distributions with more dispersion are tilted toward low usage rates; it is harder to see from the graph but they are also tilted toward higher usage in that they have a longer fat tail. In each of the graphs below, we have normalized the densities so that they have the same mean, namely $\mathrm{E}[\mathrm{n}]=\mathrm{e}=2.718$.

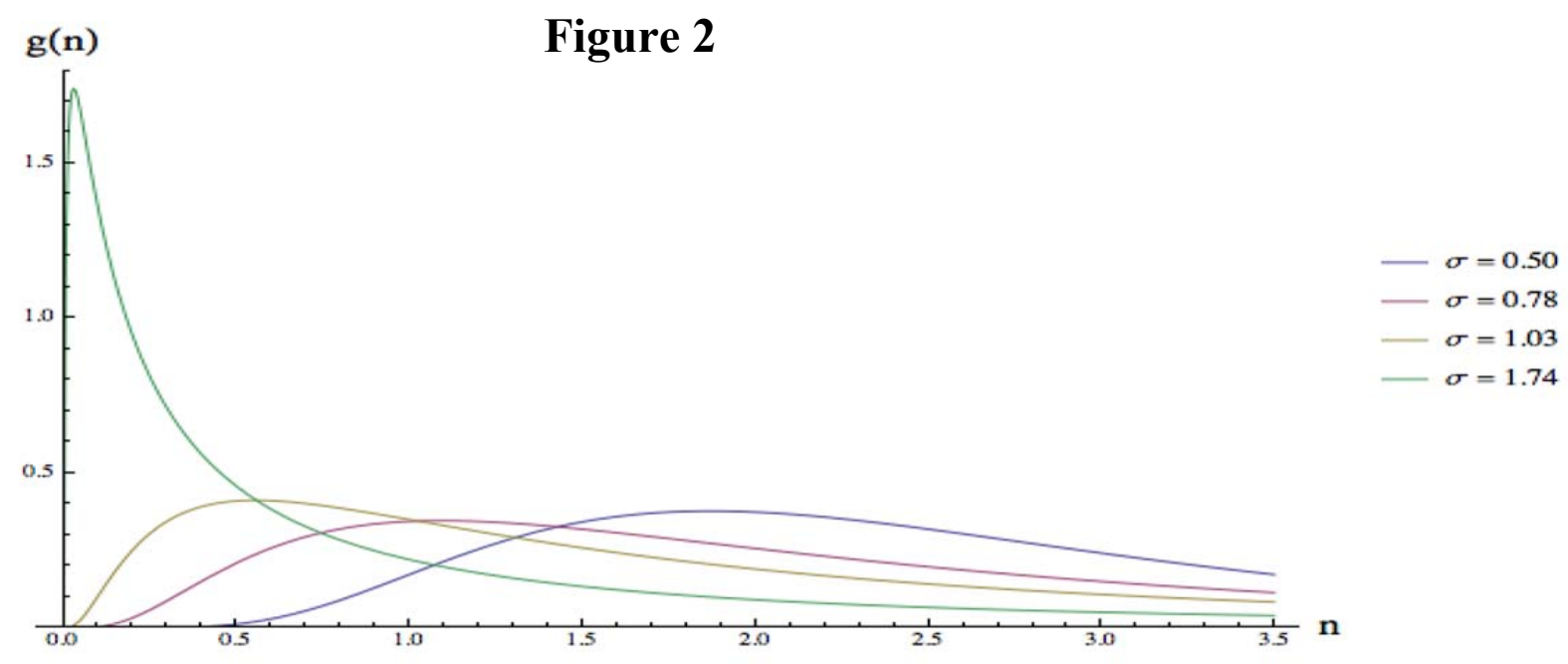

To visualize the welfare tradeoff, we illustrate the contribution to total welfare with and without metering ties. The following graph shows the result with $\sigma=0.78$.

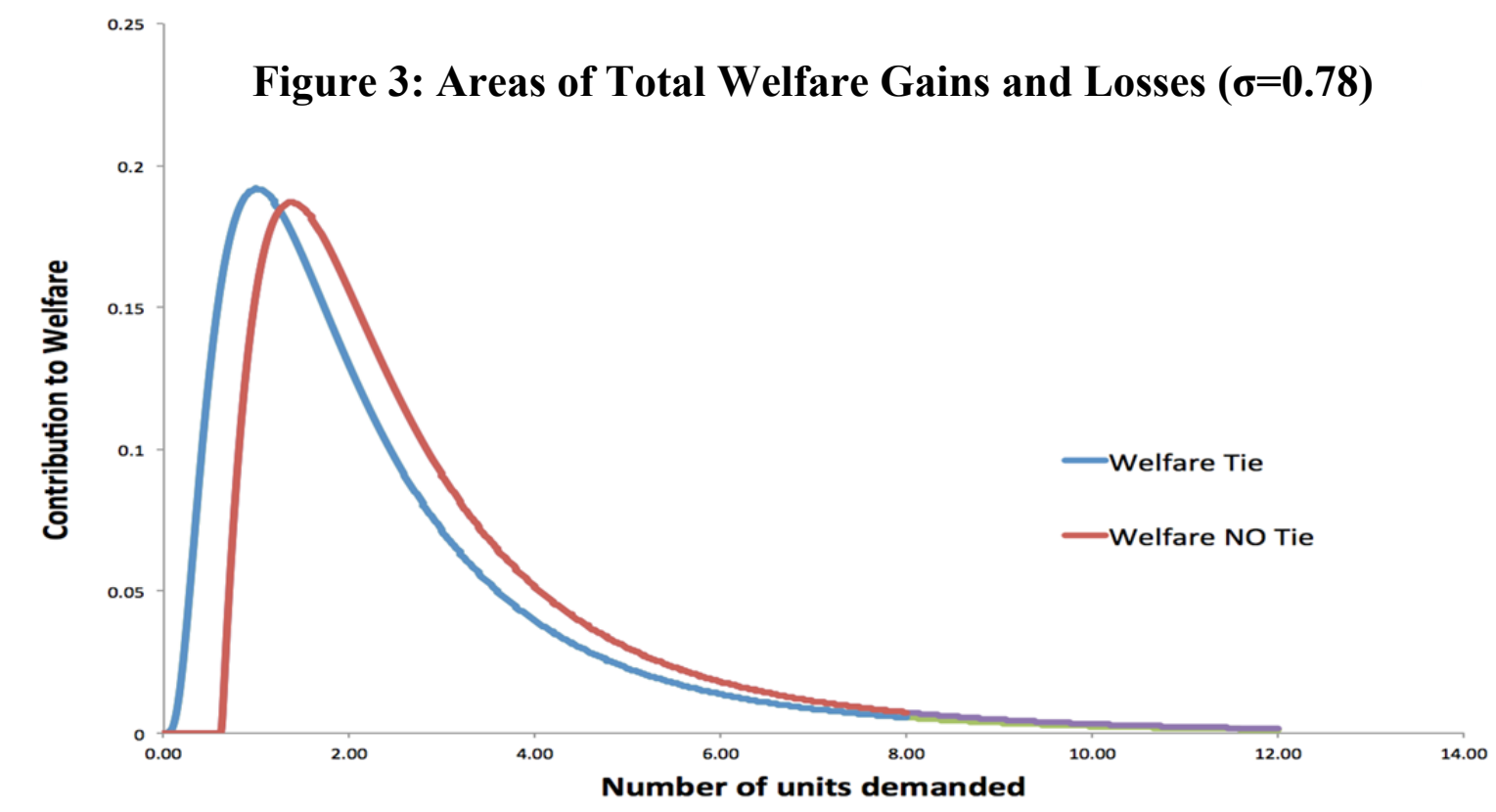

The area under the blue curve represents the contribution to total welfare from buyers who buy with the tie; the area under the red curve represents the contribution to total welfare 
from buyers who buy under the single price. With single pricing there are no buyers until $n>$ 0.62 , so that tying gets off to a head start. While tying brings in more consumers with low demand, those consumers contribute little to total welfare because they have low demand. In the case where $\sigma=0.78$, the total welfare comes out the same under the two pricing schemes.

Once again, although we have framed the analysis above in terms of tying, all the same formulas and analysis would apply if one considered the case of pure metering without any tie. Thus, with a lognormal distribution, direct second-degree price discrimination via metering is profitable and always lowers consumer welfare, and it also lowers total welfare unless at least $27 \%$ of the buyers who buy the capital good with metering failed to buy the capital good without metering.

\section{Differences With Prior Models}

As noted above, other scholars have reached the conclusion, contrary to ours, that metering ties generally raise consumer welfare and total welfare. These scholars rely on a different formal model; see Hovenkamp and Hovenkamp (2010) and Lambert (2011). Their model employs two assumptions that turn out to distort the analysis in favor of finding welfare increases.

First, Hovenkamp and Hovenkamp (2010) assume that different types of buyers vary only in a unidimensional "intensity level." In their models, consumers can be lined up in a single dimension based on how much they value the consumable. A high-value buyer starts with an initial value of, say, 10 and this falls to 0 , while a low-value buyer starts with an initial value of 2 , which declines to 0 . What that means is that in any pricing scenario, if the low-value buyer is in the market then the high-value will be, too. There is no potential for inefficient allocation.

This one-dimensionality assumption has the effect of biasing their analysis because it excludes from the analysis customers who have high usage rates but a low per-unit value, precisely the consumers who may be inefficiently priced out of the market under tying.

Second, their model evaluates a set of possible tying terms, without considering whether those terms are profit maximizing or even more profitable than a separate sale. Although it may be possible to find a combination of tying prices and a distribution of buyer preferences which leads to an ambiguous welfare result, that is irrelevant if such prices would not be seen in the market. We assume that firms pick prices to maximize profits. The relevant question is to compare welfare for the prices that firms would pick under single pricing versus metered pricing. 
Theorem 7 shows that given our market assumptions and no capital good costs, the metered prices chosen by the firm will always lower consumer welfare for any lognormal distribution of usage rates.

Even if one accepts their model, their main results are a weak application of the Pareto Principle. They accept the possibility that high-usage and even medium-usage customers may be harmed by metering. In contrast, low-intensity consumers who buy the tying product because of the lower upfront price are unambiguously better off (since they had zero utility under single pricing). Thus, provided there are any new customers brought into the market, there will be a plus to balance against a possible minus, and they consider the result unknown.

Adding up the pluses and minuses, we show in Theorems 1-3 that metering ties will reduce both consumer welfare and total welfare unless the number of customers gained outnumber those lost. The new low-intensity customers contribute less to consumer welfare than those lost. And even if the total number of customers increases, we are able to show that the net effect on consumer welfare can still be unambiguously negative, as in the lognormal case. Turning to total welfare, the results from the lognormal case show the extent to which metering needs to expand the customer set in order to offset its inefficiency. Consider the case where $\sigma=$ 0.78 , so that metering is just tied with single pricing in terms of total welfare. By Lemma 1 , the sales of the capital good under metering are $1 / 2$ and are $1 / 2\left[1-G\left(p^{*}\right)\right]=0.36$ under single pricing. ${ }^{25}$ Metering has to expand capital good sales by $37 \%(0.5 / 0.36-1)$ before total welfare is equalized.

\section{CONCLUSION}

Current tying doctrine condemns ties with market power that restrain a substantial dollar volume of sales, unless the defendant proves an offsetting procompetitive justification. Critics of current doctrine law have argued that, even without any procompetitive justification, such ties are often metering devices that create second-degree price discrimination, which they claim means they can (unlike third-degree price discrimination) increase consumer welfare and total welfare

\footnotetext{
${ }^{25}$ At $\sigma=0.78, p^{*}$ is $0.62, \ln \left(p^{*}\right) \approx-0.47$, and $\ln \left(p^{*}\right) / \sigma=-0.61$. Thus, $1 / 2\left[1-\mathrm{G}\left(\mathrm{p}^{*}\right]=1 / 2[1-\Phi(-0.61)]=0.36\right.$.
} 
without increasing output. More generally, critics claim that metering ties generally increase consumer welfare and total welfare.

This paper shows that there is no reason to think that second-degree pricing discrimination in general, or metering ties in particular, are better forms of price discrimination than the more frequently analyzed third-degree versions. We prove that when a firm has market power over a capital good that is used with a competitive consumable, then (just like third-degree price discrimination) metering ties and second-degree price discrimination lower consumer welfare and total welfare unless they increase capital good output. This proof supports, at a minimum, requiring defendants to show that their metering ties have the procompetitive effect of expanding capital good output. Some might argue that an increase in consumable output would be sufficient to demonstrate an increase in total welfare. We prove that this is true if the capital good is both costless and provided for free, but it is not true more generally. Nor does the proposition apply to consumer welfare.

Even when metering ties increase capital good output, it does not follow that they generally increase consumer welfare. To the contrary, we prove that for all uniform and lognormal distributions of usage intensity, metering ties harm consumer welfare. While it is possible to posit other distributions where consumer welfare rises, our models support current doctrine's presumption that ties harm consumer welfare. This presumption should be rebuttable based on demonstrating efficiencies not captured in our model or a showing that different assumptions fit the case at hand and make it more likely that the metering tie benefits consumer welfare.

Even if antitrust law changed the relevant legal standard to total welfare, there is no basis for the claim that metering ties generally increase welfare. With a lognormal distribution of usage rates, metering ties reduce total welfare unless the dispersion of the desired usage of the metered good is very large. Moreover, the usage dispersion must be even higher if (as plausible) we assume some dissipation of profits because of implementation costs and other factors. Our analysis thus supports a presumption that metering ties lower total welfare unless the defendant can prove either a very large usage dispersion, efficiencies, or that other assumptions better fit the case and lead to different results.

As noted above, a necessary (but not sufficient) step to showing that a tie increases consumer welfare or total welfare is to show an increase in the sales of the capital good. 
Sometimes, we might have a period before and after the tie is imposed and be able to control for other changes that occurred over time, or we might have geographic markets where the tie was and was not imposed and be able to control for differences between those markets. Another approach is to estimate the counterfactual case of what capital good sales would have been with single pricing, using market data to estimate demand and calculate the optimal single price with that demand. If we have cost data and demand estimates, we can also take the next step of calculating welfare directly. With a lognormal distribution, we can also model the change in welfare by estimating the dispersion in $n .^{26}$ These approaches do not seem more difficult that the sort of analysis ordinarily done to analyze mergers or calculate damages from cartels or other antitrust violations.

It is tempting to imagine that since perfect price discrimination improves total welfare, any move towards more price discrimination will lead in that same direction. But while giving a firm with market power more price discrimination tools will generally raise its profits, this gain may come from consumers and result in lower overall efficiency. The advantage of metering is that it is well designed to handle heterogeneity in desired usage. The disadvantage of metering is that it excludes consumers who have a high overall valuation that comes from wanting a large number of units, each with a relatively low value. The advantage of a single price is that it is maximally efficient given the sales that occur. Under single pricing a firm with market power will inefficiently restrict supply, but it does so in the most efficient manner possible. We may not like the effect of market power. The results of this paper show that we might like even less the results when we allow a firm with market power the ability to do an even better job exploiting that power.

\footnotetext{
${ }^{26}$ The customers who purchase under metering do not restrict their usage. This allows us to fit a lognormal distribution on the observed demand for consumables.
} 


\section{REFERENCES}

Areeda, Phillip E., and Herbert Hovenkamp. 2011. Antitrust Law: An Analysis of Antitrust Principles and Their Application, $3^{\text {rd }}$ ed. New York: Aspen Law \& Business.

Burstein, M.L. 1960a. "The Economics of Tie-In Sales," 42 Review of Economics and Statistics 68-73.

. 1960b. "A Theory of Full-Line Forcing," 55 Northwestern University Law Review 7391.

Button, Kenneth J., and Thomas G. Weyman-Jones. 1992. "Ownership Structure, Institutional Organization and Measured X-Efficiency," 82 (2) American Economic Review 439-45.

Carlton, Dennis W., and Ken Heyer. 2008. "Extraction vs. Extension: The Basis for Formulating Antitrust Policy Towards Single-Firm Conduct," 4 (2) Competition Policy International 285-305.

Carlton, Dennis W., and Michael Waldman. 2012. "Brantley Versus NBC Universal: Where's the Beef?," 8 (2) Competition Policy International 1-12.

Crane, Daniel. 2012. "Tying and Consumer Harm," 8 (2) Competition Policy International

Economides, Nicholas. 2012. "Tying, Bundling, and Loyalty/Requirement Rebates," in E. Elhauge, ed., Research Handbook on the Economics of Antitrust Law. 121-143. Northampton, Mass.: Edward Elgar Publishing.

Elhauge, Einer. 2003. "Defining Better Monopolization Standards," 56 Stanford Law Review 253-344.

2009. "Tying, Bundled Discounts, and the Death of the Single Monopoly Profit Theory," 123 (2) Harvard Law Review 397-481.

—. 2010. "The Failed Resurrection of the Single Monopoly Profit Theory," 6 (1) Competition Policy International 155-209.

- 2011. United States Antitrust Law and Economics, $2^{\text {nd }}$ ed. New York: Foundation Press.

—. Forthcoming. "Rehabilitating Jefferson Parish: Why Ties Without A Substantial Foreclosure Share Should Not Be Per Se Legal," Antitrust Law Journal.

Fisher, Franklin M. 1985. "The Social Costs of Monopoly and Regulation: Posner Reconsidered," 93 (2) Journal of Political Economy 410-416.

Frantz, Roger. 1992. "X-Efficiency and Allocative Efficiency: What Have We Learned?," 82 (2) American Economic Review 434-438.

Greenlee, Patrick, David Reitman, and David S. Sibley. 2008. "An Antitrust Analysis of Bundled Loyalty Discounts," 26 (5) International Journal of Industrial Organization 1132-1152.

Grimes, Warren S., and Lawrence A. Sullivan. 2007. "Illinois Tool Works, Inc. v. Independent Ink, Inc.: Requirements Tie-Ins and Intellectual Property," 13 (2) Southwestern Journal of Law and Trade in the Americas 335-354.

Hovenkamp, Erik and Herbert Hovenkamp. 2010. "Tying Arrangements and Antitrust Harm," 52 Arizona Law Review 925-976. 
Lambert, Thomas A. 2011. "Appropriate Liability Rules for Tying and Bundled Discounting," 72 Ohio State Law Journal 909-981.

Layson, Stephen K. 1998. "Third-Degree Price Discrimination with Interdependent Demands," 46 (4) Journal of Industrial Economics 511-524.

Leibenstein, Harvey. 1966. "Allocative Efficiency vs. "X-Efficiency," 56 (3) American Economic Review 392-415.

. 1978a. "X-Inefficiency Xists: Reply to an Xorcist," 68 (1) American Economic Review 203-211.

. 1978b. "On the Basic Proposition of X-Efficiency Theory," 68 (2) American Economic Review 328-332.

Motta, Massimo. 2004. Competition Policy: Theory and Practice. New York: Cambridge University Press.

Mathewson, Frank, and Ralph Winter. 1997. "Tying as a Response to Demand Uncertainty," 28 (3) RAND Journal of Economics 566-583.

Nalebuff, Barry. 2005. “Exclusionary Bundling," 50 (3) Antitrust Bulletin 321-370.

. 2009. "Price Discrimination and Welfare," 5 (2) Competition Policy International 221241.

Posner, Richard A. 1975. "The Social Costs of Monopoly and Regulation," 83 (4) Journal of Political Economy 807-828.

- 2005. "Vertical Restraints and Antitrust Policy," 72 (1) University of Chicago Law Review 229-241.

Primeaux, Walter J. 1977. “An Assessment of X-Efficiency Gained Through Competition,” 59 (1) Review of Economics and Statistics 105-108.

Robinson, Joan. 1969. The Economics of Imperfect Competition, $2^{\text {nd }}$ ed. London: Macmillan.

Scherer, Frederic M., and David Ross. 1990. Industrial Market Structure and Economic Performance, $3^{\text {rd }}$ ed. Boston: Houghton Mifflin.

Schmalensee, Richard. 1981. "Output and Welfare Implications of Monopolistic Third-Degree Price Discrimination," 71 (1) American Economic Review 242-247.

Schwartz, Marius. 1990. "Third-Degree Price Discrimination and Output: Generalizing a Welfare Result," 80 (5) American Economic Review 1259-62.

Semeraro, Steven. 2010. "Should Antitrust Condemn Tying Arrangements that Increase Price Without Restraining Competition?," 123 (2) Harvard Law Review 30-37

Shelton, John P. 1967. “Allocative Efficiency vs. 'X-Efficiency': Comment," 57 (5) American Economic Review 1252-1258.

Tirole, Jean. 1988. The Theory of Industrial Organization. Cambridge, Mass.: MIT Press.

Varian, Hal. 1985. "Price Discrimination and Social Welfare," 75 (4) American Economic Review 870-875.

. 1989. "Price Discrimination," in R. Schmalensee and R. D. Willig, eds., Handbook of Industrial Organization, Volume 1. 597-654. San Diego: Elsevier. 


\section{Mathematical Appendix}

Theorem 7: Under our Market Assumptions, a small reduction in metering leads to an increase in both consumer welfare and total welfare.

The monopolist chooses $m$ and $p$ jointly to maximize profits. We could equivalently say that the monopolist chooses $m$ where the upfront price is $p(m)$. To prove Theorem 7 , we need show

$$
\frac{d C S}{d m}<0 \text { and } \frac{d T S}{d m}<0
$$

at the $m$ that maximizes profits. If so, a small reduction in $m$ will improve consumer and total welfare. Because $m$ and $p(m)$ are chosen by the monopolist to maximize profits, it follows immediately that $\frac{d \Pi}{d m}=0$. Thus the change in consumer surplus is the same as the change in total welfare. And the change in consumer surplus is just equal to the change in the amount existing consumers pay under the new pricing scheme. (This follows as the lost marginal consumers had no surplus and the level of consumption is fixed at $n$ or 0 .) To determine the change in payments, we begin by calculating $\frac{d p}{d m}$.

$$
\begin{gathered}
\text { Profits }=\int_{\frac{p}{1-m}}^{\infty}\left(n\left(m-c_{1}\right)+p-c_{0}\right)\left(1-m-\frac{p}{n}\right) g(n) d n . \\
\frac{d \text { Profits }}{d p}=\int_{\frac{p}{1-m}}^{\infty}\left(1+c_{1}-2 m-\frac{2 p-c_{0}}{n}\right) g(n) d n=0 .
\end{gathered}
$$

The first-order condition in (A2) defines $p(m)$. Taking the derivative with respect to $m$ provides the equation for $\frac{d p}{d m}$. Note that at the profit-maximizing $m$,

$$
p=\frac{c_{0}}{2}, \quad m=\frac{1+c_{1}}{2} .
$$

Thus the integrand in (A2) is zero for all values of $n$ at the profit-maximizing value of $m$, so that we can ignore that effect of the change in the range of integration.

$$
\begin{gathered}
\int_{\frac{p}{1-m}}^{\infty}\left(-2-\frac{2}{n} \frac{d p}{d m}\right) g(n) d n=0 \\
\frac{d p}{d m}=-H\left[n \mid n \geq \frac{p}{1-m}\right],
\end{gathered}
$$

where $H[n]$ is the harmonic mean of $n$, conditional on $n$ being at least $\frac{p}{1-m}$. 
We can now compute the change in consumers' payments (and thus change in consumer surplus). Demand can be broken into two parts:

$$
\begin{aligned}
\text { Capital Good Demand }= & \int_{\frac{p}{1-m}}^{\infty}\left(1-m-\frac{p}{n}\right) g(n) d n \\
= & \left(1-G\left(\frac{p}{1-m}\right)\right)\left(1-m-\frac{p}{H}\right) ; \\
\text { Consumable Good Demand }= & \int_{\frac{p}{1-m}}^{\infty} n\left(1-m-\frac{p}{n}\right) g(n) d n \\
& =\left(1-G\left(\frac{p}{1-m}\right)\right)((1-m) E[n]-p)
\end{aligned}
$$

As $m$ increases, the consumers pay $d m$ more on consumables and $\frac{d p}{d m} d m$ less on the capital good:

$$
\begin{aligned}
\frac{d C S}{d m} & =-1 * \text { Consumable Good Demand }+H * \text { Capital Good Demand } \\
& =\left[1-G\left(\frac{p}{1-m}\right)\right]\left(-(1-m) E[n]+p+H[n]\left(1-m-\frac{p}{H[n]}\right)\right) \\
& =\left[1-G\left(\frac{p}{1-m}\right)\right](1-m)(H[n]-E[n])<0 .
\end{aligned}
$$

where $H[n]$ and $E[n]$ are the harmonic and arithmetic means conditional on $n$ being greater than

$\frac{p}{1-m}$. The final inequality follows from the fact that the arithmetic mean is always greater than the harmonic mean. The inequality is strict provided that the density is not all concentrated on a single mass point, which is ruled out by out Market Assumption. Other than the no-mass point, we do not require any assumption on the distribution $g(n)$.

Before proving Theorems 8 and 9, we employ two normalizations to simplify the mathematics without loss of generality.

\section{Lemma 2: We can assume that $c_{1}=0$ and the scale factor for the lognormal, $\mu$, is 0 , both without loss of generality.}

Proof: First, consider the case where variable costs are zero. Since fixed costs are zero, profits, consumer surplus, and total profits are proportional to the scale of per-unit valuations. Thus we could replace the $[0,1]$ range with $[0, v]$ and this would have no impact on any comparison between single pricing and metering. 
Now imagine that there are positive costs associated with the consumable. None of the comparisons change if we subtract that variable cost from the per-unit valuation. In this event, the metered price should be thought of as a markup over cost. Instead of having a uniform distribution of valuations over $[0, v]$, the distribution of per-unit values would be uniform over [$\left.\mathrm{c}_{1}, v-\mathrm{c}_{1}\right]$. And since consumers with negative valuations won't enter the market, this is equivalent to a uniform distribution (with fewer total consumers) over $\left[0, v-\mathrm{c}_{1}\right]$. Then we can further scale the range so that $v-c_{1}=1$, and we are back to the uniform distribution over $[0,1]$. Thus we can normalize the unit cost of the consumable to zero without loss of generality.

The second normalization is the scale of $n$. In the case of metering, it follows directly that the total surplus is proportional to the number of units purchased. Thus if each customer's demand doubles, profits and surpluses double. In the case of a single profit-maximizing price, the price is proportional to the scale of demand. Thus if each customer's demand doubles, the profit-maximizing price doubles, as does profits, consumer surplus, and total surplus. Since both surpluses are proportional to scale, which one is bigger does not depend on the scale. Thus, without loss of generality, we can scale demand so that $\mathrm{E}[\ln (n)]=0$, where $\mathrm{E}$ is the expectation operator. In the case of the lognormal distribution, this means that $\mu=0$.

\section{Theorem 8: Under our Market Assumptions with $\mathrm{c}_{0}=0$, metering ties always lower consumer surplus for any lognormal distribution of buyer usage rates.}

Proof: By Lemma 2, we can set $\mathrm{c}_{1}=0$ and $\mu=0$. Without tying, the maximum consumer surplus for consumers of type $n$ is $n-p$ and the minimum surplus is 0 . Thus the average consumer surplus for type $n$ consumers is $\frac{n-p}{2}$.

$$
\begin{aligned}
\text { Consumer Surplus } & =\left[\int_{p}^{\infty} \frac{n-p}{2}\left(1-\frac{p}{n}\right) g(n) d n\right] \\
& =\left[\int_{p}^{\infty}\left(\frac{n}{2}-p+\frac{p^{2}}{2 n}\right) g(n) d n\right]
\end{aligned}
$$

By substituting in the value of $p^{*}$ from equation (2), we find

$$
\begin{aligned}
\text { Consumer Surplus } & =\left[\int_{p^{*}}^{\infty}\left(\frac{n}{2}-p^{*}+\frac{p^{*}}{4}\right) g(n) d n\right] \\
& =\left[\int_{p^{*}}^{\infty}\left(\frac{n}{2}-\frac{3 p^{*}}{4}\right) g(n) d n\right]
\end{aligned}
$$


Applying the lognormal density (with the normalization of $\mu=0$ ) and using the variable transformation $y=\ln (n)$, we get:

Consumer Surplus

$$
\begin{aligned}
& =\frac{1}{2}\left[\int_{\ln \left(p^{*}\right)}^{\infty} e^{y} \frac{1}{\sqrt{2 \pi} \sigma} \mathrm{e}^{-\frac{y^{2}}{2 \sigma^{2}}} d y-\frac{3 p^{*}}{2} \int_{\ln \left(p^{*}\right)}^{\infty} \frac{1}{\sqrt{2 \pi} \sigma} \mathrm{e}^{-\frac{y^{2}}{2 \sigma^{2}}} d y\right] \\
& =\frac{1}{2}\left[e^{\frac{1}{2} \sigma^{2}} \int_{\ln \left(p^{*}\right)}^{\infty} \frac{1}{\sqrt{2 \pi} \sigma} \mathrm{e}^{-\frac{1}{2 \sigma^{2}}\left(y-\sigma^{2}\right)^{2}} d y-\frac{3 p^{*}}{2} \int_{\ln \left(p^{*}\right)}^{\infty} \frac{1}{\sqrt{2 \pi} \sigma} \mathrm{e}^{-\frac{1}{2 \sigma^{2}} y^{2}} d y\right] \\
& =\frac{1}{2}\left[e^{\frac{1}{2} \sigma^{2}} \int_{\frac{\ln \left(p^{*}\right)}{\sigma}-\sigma}^{\infty} \frac{1}{\sqrt{2 \pi}} \mathrm{e}^{-\frac{1}{2} z^{2}} d z-\frac{3 p^{*}}{2} \int_{\frac{\ln \left(p^{*}\right)}{\sigma}}^{\infty} \frac{1}{\sqrt{2 \pi}} \mathrm{e}^{-\frac{1}{2} q^{2}} d q\right]
\end{aligned}
$$

where we employ the transformations $z=\frac{y-\sigma^{2}}{\sigma}$ and $q=\frac{y}{\sigma}$. Note that $\sigma$ is the standard deviation parameter in the lognormal.

Define $\Phi()$ as the cumulative density of a standard normal distribution (mean 0 and standard deviation of 1).

$$
\text { Consumer Surplus }=\frac{1}{2}\left[e^{\frac{1}{2} \sigma^{2}}\left[1-\Phi\left(\frac{\ln \left(p^{*}\right)}{\sigma}-\sigma\right)\right]-\frac{3 p^{*}}{2}\left[1-\Phi\left(\frac{\ln \left(p^{*}\right)}{\sigma}\right)\right]\right] .
$$

The value of $p^{*}$ is defined by (3). Applying the lognormal density as above, we find an equation for $\mathrm{p}^{*}$ :

$$
p^{*}=\frac{\frac{1}{2} e^{-\frac{1}{2} \sigma^{2}}\left[1-\Phi\left(\frac{\ln \left(p^{*}\right)}{\sigma}\right)\right]}{1-\Phi\left(\frac{\ln \left(p^{*}\right)}{\sigma}+\sigma\right)}
$$

Note that $p^{*}$ is an (implicit) function entirely of $\sigma$. Below is a graph of the single profitmaximizing price, $p^{*}(\sigma)$. 


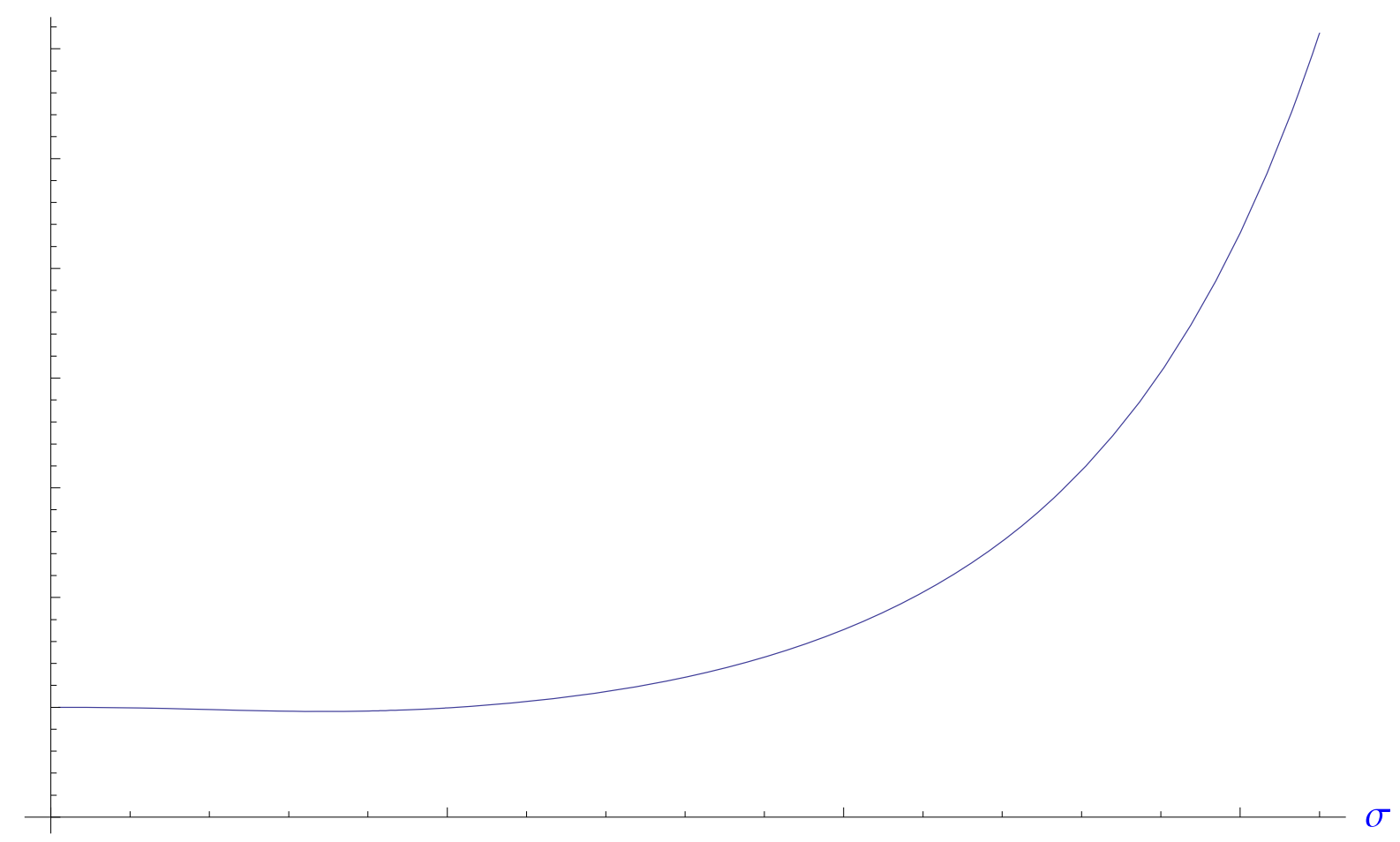

Substituting in the value of $p^{*}$ but leaving $\ln \left(p^{*}\right)$ in the equation, we find:

$$
\text { Consumer Surplus }=\frac{1}{2}\left[e^{\frac{1}{2} \sigma^{2}}\left[1-\Phi\left(\frac{\ln (p)}{\sigma}-\sigma\right)\right]-\frac{\frac{3}{4} e^{-\frac{1}{2} \sigma^{2}}\left[1-\Phi\left(\frac{\ln (p)}{\sigma}\right)\right]^{2}}{1-\Phi\left(\frac{\ln (p)}{\sigma}+\sigma\right)}\right]
$$

As a consistency check, note that if $\sigma$ is sufficiently small, $p^{*}$ converges to $1 / 2$ and Consumer Surplus converges to $1 / 8$.

With a metering tie,

Consumer Surplus $=\frac{1}{2} * \frac{1}{4} * E[n]=\frac{1}{8} e^{\frac{1}{2} \sigma^{2}}$.

By factoring out $\frac{1}{2} e^{\frac{1}{2} \sigma^{2}}$ we see that metering ties will reduce consumer welfare if

$$
\left[\left[1-\Phi\left(\frac{\ln (p)}{\sigma}-\sigma\right)-\frac{\frac{3}{4} e^{-\sigma^{2}}\left[1-\Phi\left(\frac{\ln (p)}{\sigma}\right)\right]^{2}}{1-\Phi\left(\frac{\ln (p)}{\sigma}+\sigma\right)}\right]^{2} \geq \frac{1}{4}\right.
$$

The graph below is the left-hand side of the above equation. Because it exceeds 0.25 for all values of $\sigma$, consumer welfare is always lower with a metering tie. 


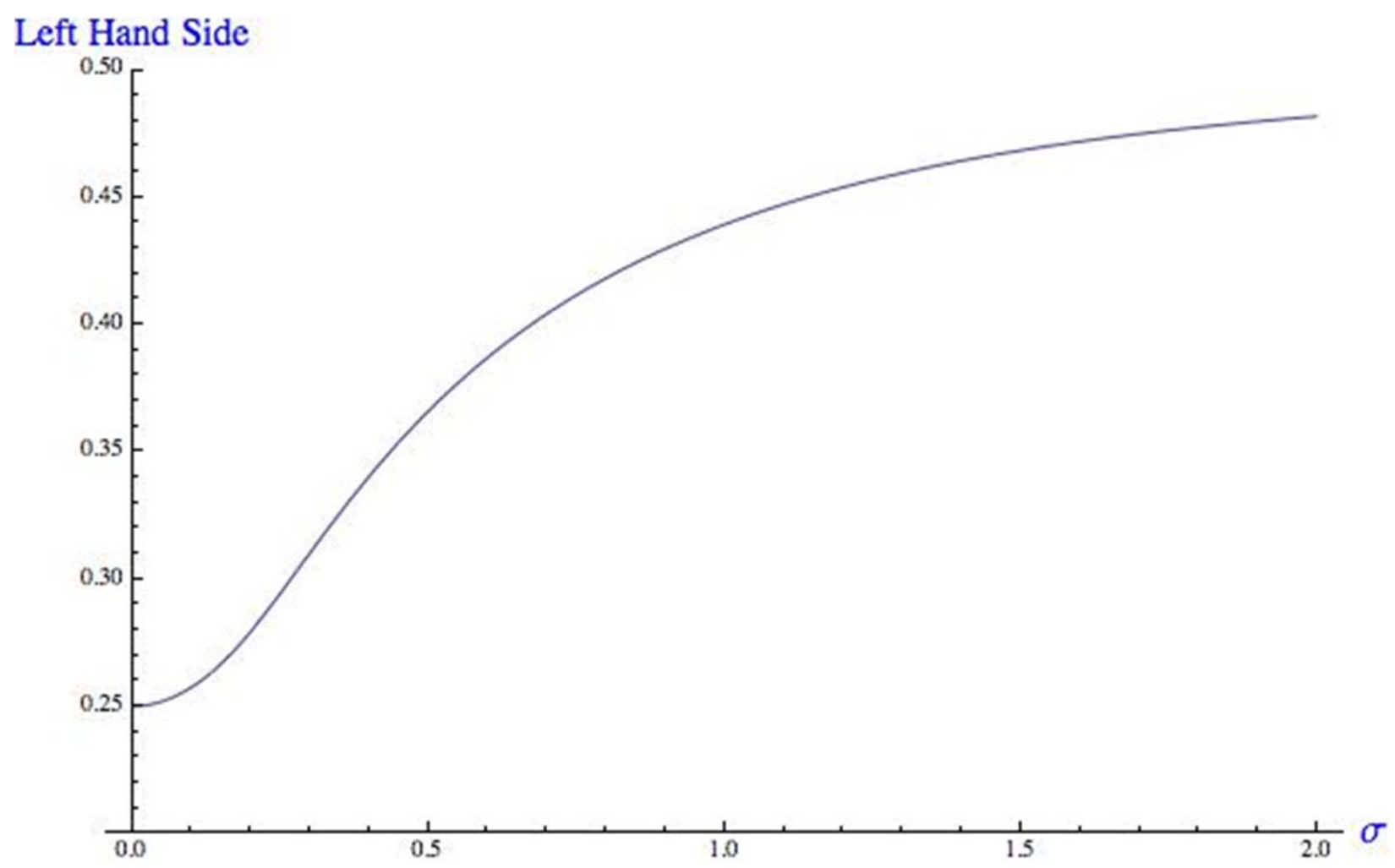

Corollary: Under our Market Assumptions with $\mathbf{c}_{0}=0$, metering ties always lower consumer surplus for any uniform distribution of buyer usage rates.

Proof: We are able to use the expressions for consumer surplus (Eq. A5) and pricing (Eq. 3) to show that the result in Theorem 7 also applies to the uniform distribution. Let $n$ be distributed uniformly over $[L, H]$. If $p^{*} \leq L$ then by Theorems 5 and 6 , we know that profits are higher and total welfare is lower, so consumer welfare must also have fallen. Thus the remaining case is when $(L, H)$ are such that $p^{*}>L$.

$$
\text { Consumer Surplus Metering }=\frac{1}{8} E[n]=\frac{H+L}{16} .
$$

Consumer Surplus Single Price $=\int_{p^{*}}^{H}\left(\frac{n}{2}-\frac{3 p^{*}}{4}\right) g(n) d n$

$$
\begin{gathered}
=\left[\frac{H+p^{*}}{4}-\frac{3 p^{*}}{4}\right]\left[H-p^{*}\right] g \\
=\left[\frac{H-2 p^{*}}{4}\right]\left[H-p^{*}\right] g .
\end{gathered}
$$

Thus consumer surplus is higher under single pricing provided 


$$
\begin{aligned}
\frac{H-2 p^{*}}{4}\left[H-p^{*}\right] g \geq \frac{H+L}{16} \\
{\left[4 H-8 p^{*}\right]\left[H-p^{*}\right] \geq H^{2}-L^{2} }
\end{aligned}
$$

as $g=1 /(H-L)$. In the uniform case, there is a simple solution for $p^{*}$.

$$
\begin{gathered}
2 p^{*}=\frac{H-p^{*}}{\ln \left(\frac{H}{P}\right)} \text { or } 2=\frac{\frac{H}{p^{*}}-1}{\left(\ln \left(\frac{H}{p^{*}}\right)\right)} \\
\frac{H}{p^{*}}=3.51
\end{gathered}
$$

Substituting this ratio into (A3) confirms the result:

$$
6.04 * 2.51 p^{* 2}=15.16 p^{2}>12.32 p^{2} \geq 3.51^{2} p^{* 2}-L^{2}
$$

Theorem 9. Under our Market Assumptions with $c_{0}=0$ and a lognormal distribution of usage rates $n$, where $\mu$ and $\sigma$ are the mean and standard deviation of the natural $\log$ of $n$, metering ties will lower total welfare for any standard deviation $\sigma$ that is less than 0.78 .

Proof: First we consider the total surplus with a metering tie. Once we apply the normalization, the profit-maximizing metered price is $1 / 2$. This is true no matter how many units are demanded. Thus the average unit valuation among those who purchase is $3 / 4$ and half purchase the good, leading to profits of $1 / 4$, consumer surplus of $1 / 8$, and a total surplus of $3 / 8$ per unit. Adding up across all consumer types, the total surplus with a metering tie is $\frac{3}{8} E[n]$. Note that if fraction $d$ of profits are dissipated, then total surplus falls to $\frac{3-2 d}{8} E[n]$.

In the case of a lognormal distribution, $E[n]=e^{\mu+\frac{1}{2} \sigma^{2}}=e^{\frac{1}{2} \sigma^{2}}$ (given our scaling normalization that $\mu=0$ ), which means that with a metering tie

$$
\text { Expected Total Surplus }=\frac{3}{8} e^{\frac{1}{2} \sigma^{2}} .
$$

We turn to the case with a single profit-maximizing price of $p^{*}$. Among those of type $n$ who purchase the capital good, the minimum value they receive is $p^{*}$ and the maximum value is $n$, so that the average value is $(1 / 2)\left(n+p^{*}\right)$. The fraction that purchase the capital good is $[1-$ $\left.p^{*} / n\right]$. Because the lowest valuation of $a$ that can lead to a purchase is $p^{*}$ and the highest $a$ is 1 , the lowest $n$ for which purchases will be made with a single price is $p^{*}$. Thus:

$$
\text { Total Surplus }=\int_{p^{*}}^{\infty}\left(\frac{n+p^{*}}{2}\right)\left(1-\frac{p^{*}}{n}\right) g(n) d n
$$




$$
=\frac{1}{2} \int_{p^{*}}^{\infty}\left(n-\frac{p^{* 2}}{n}\right) g(n) d n .
$$

By substituting the equality in (2), we have

$$
\text { Total Surplus }=\frac{1}{2}\left[\int_{p^{*}}^{\infty} n g(n) d n-\frac{p^{*}}{2}\left[1-G\left(p^{*}\right)\right]\right]
$$

Applying the same transformations as was done in the proof of Theorem 7, we find

Total Surplus (with a single profit-maximizing price) $=$

$$
=\frac{1}{2}\left[e^{\frac{1}{2} \sigma^{2}}\left[1-\Phi\left(\frac{\ln \left(p^{*}\right)}{\sigma}-\sigma\right)\right]-\frac{\frac{1}{4} e^{-\frac{1}{2} \sigma^{2}}\left[1-\Phi\left(\frac{\ln \left(p^{*}\right)}{\sigma}\right)\right]^{2}}{1-\Phi\left(\frac{\ln \left(p^{*}\right)}{\sigma}+\sigma\right)}\right]
$$

Metering:

Total surplus with a metering tie is $\frac{3}{8} e^{\frac{1}{2} \sigma^{2}}$. Thus, total surplus is lower with a metering tie if

$$
\frac{1}{2}\left[e^{\frac{1}{2} \sigma^{2}}\left[1-\Phi\left(\frac{\ln (p)}{\sigma}-\sigma\right)\right]-\frac{\frac{1}{4} e^{-\frac{1}{2} \sigma^{2}}\left[1-\Phi\left(\frac{\ln (p)}{\sigma}\right)\right]^{2}}{1-\Phi\left(\frac{\ln (p)}{\sigma}+\sigma\right)}\right]^{2} \frac{3}{8} e^{\frac{1}{2} \sigma^{2}}
$$

Multiplying both sides by 2 and factoring out an $e^{\frac{1}{2} \sigma^{2}}$ leads to the conclusion that metering ties lower total welfare if

$$
1-\Phi\left(\frac{\ln (p)}{\sigma}-\sigma\right)-\frac{\frac{1}{4} e^{-\sigma^{2}}\left[1-\Phi\left(\frac{\ln (p)}{\sigma}\right)\right]^{2}}{1-\Phi\left(\frac{\ln (p)}{\sigma}+\sigma\right)}>\frac{3}{4}
$$

Metering ties reduce total welfare whenever the left side of equation (A2) is greater than $3 / 4$. The following graphs the left side of equation (A2) on the $\mathrm{Y}$ axis, with $\sigma$ on the $\mathrm{X}$ axis. We see that this inequality holds for values of $\sigma$ below 0.78 . 


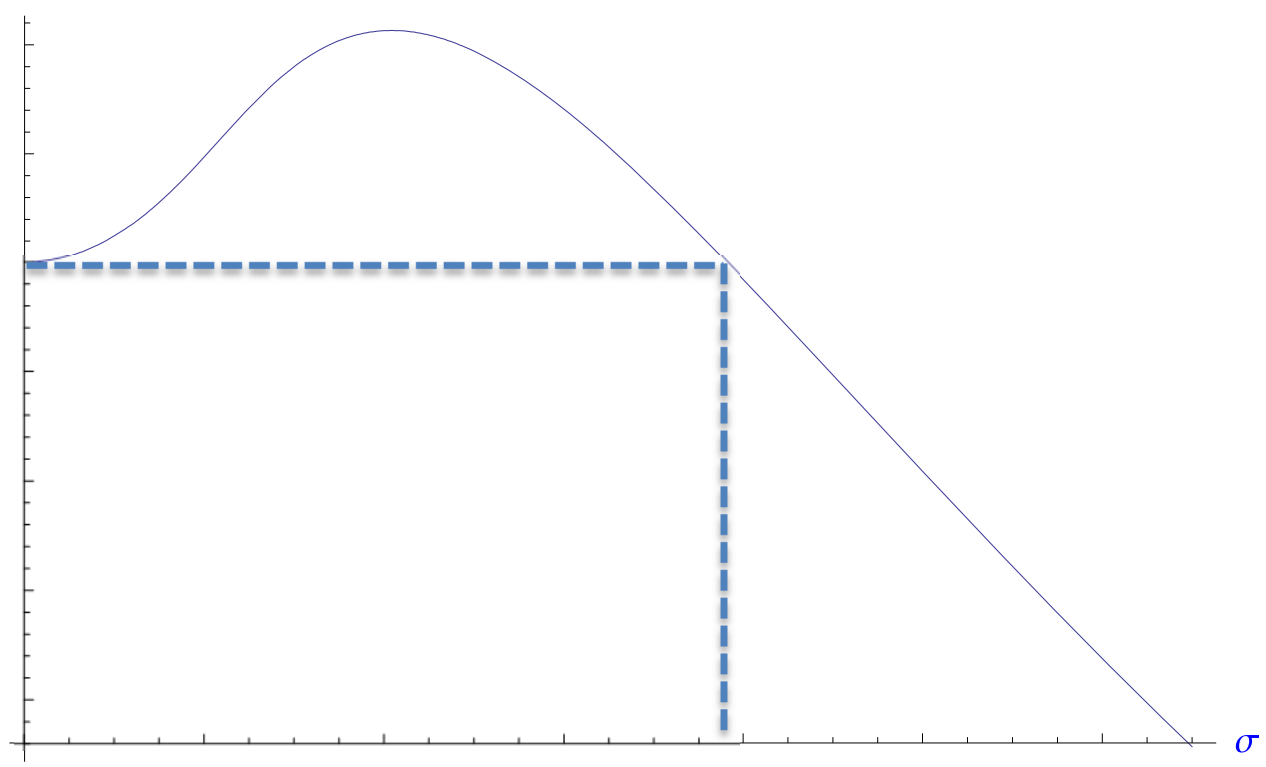

Corollary. If metering leads to dissipation of fraction $d$ of incremental profits then single pricing leads to greater total surplus provided:

$$
1-\Phi\left(\frac{\ln (p)}{\sigma}-\sigma\right)-\frac{\frac{1+2 d}{4} e^{-\sigma^{2}}\left[1-\Phi\left(\frac{\ln (p)}{\sigma}\right)\right]^{2}}{1-\Phi\left(\frac{\ln (p)}{\sigma}+\sigma\right)}>\frac{3-2 d}{4}
$$

The dissipation only applies to the incremental profits from metering over single pricing. Thus we replace the profit component of total surplus under metering by Metering Profits $-d *$ (Metering Profits - Single Pricing Profits). This is what leads to the $2 d$ terms above.

If $d=10 \%$, then single pricing leads to higher surplus for $\sigma$ below 1.03 . If $d=25 \%$, then single pricing leads to higher surplus for $\sigma$ below 1.74 . And if $d=33 \%$, then single pricing leads to higher surplus for $\sigma$ below 2.65 . 